\title{
Metadichol@, a Novel Nano Lipid Formulation that Inhibits SARS-COV-2 and a Multitude of Pathological Viruses in vitro
}

Palayakotai Raghavan ( $\nabla$ raghavan@nanorxinc.com )

NANORX Inc.

Research

Keywords: Coronavirus, SARS-COV-2, COVID-19, ACE, ACE2, TMPRSS2, VDR, Metadichol

Posted Date: November 3rd, 2021

DOI: https://doi.org/10.21203/rs.3.rs-34021/v9

License: (c) (1) This work is licensed under a Creative Commons Attribution 4.0 International License.

Read Full License

Version of Record: A version of this preprint was published at BioMed Research International on January 15th, 2022. See the published version at https://doi.org/10.1155/2022/1558860. 


\section{Abstract}

Increasing outbreaks of new pathogenic viruses have promoted the exploration of novel alternatives to time-consuming vaccines. Thus, it is necessary to develop a universal approach to halt the spread of new and unknown viruses as they are discovered. One such promising approach is to target lipid membranes, which are common to all viruses and bacteria. The ongoing severe acute respiratory syndrome coronavirus 2 (SARS-CoV-2) pandemic has reaffirmed the importance of interactions between the virus envelope and the host cell plasma membrane as a critical mechanism of infection. Metadicholß, a nano lipid emulsion of long chain alcohols, has been demonstrated as a strong candidate that inhibits the proliferation of SARS-CoV-2. Naturally derived substances, such as long-chain saturated lipid alcohols, reduce viral infectivity, including that of coronaviruses (such as SARS-CoV-2) by modifying their lipiddependent attachment mechanism to human host cells. The receptor ACE2 mediates the entry of SARSCoV-2 into the host cells, whereas the serine protease TMPRSS2 primes the viral S protein. In this study, Metadichol ${ }^{\circledR}$ was found to be 270 times more potent an inhibitor of TMPRSS2 $\left(\mathrm{EC}_{50}=96 \mathrm{ng} / \mathrm{ml}\right)$ than Camostat mesylate $\left(\mathrm{EC}_{50}=26000 \mathrm{ng} / \mathrm{mL}\right)$. Additionally, it inhibits $\mathrm{ACE}$ with an $\mathrm{EC}_{50}$ of $71 \mathrm{ng} / \mathrm{mL}$, but very weak inhibitor of ACE2 at an $\mathrm{EC}_{50}$ of $31 \mu \mathrm{g} / \mathrm{ml}$. Furthermore, the live viral assay performed in Caco-2 cells revealed that Metadichol $\circledast$ inhibits SARS-CoV-2 replication at an $\mathrm{EC}_{90}$ of $0.16 \mu \mathrm{g} / \mathrm{ml}$. Moreover, Metadichol ${ }^{\circledR}$ had an $\mathrm{EC}_{90}$ of $0.00037 \mu \mathrm{M}$, making it 2081 and 3371 times more potent than Remdesivir $\left(\mathrm{EC}_{50}=0.77 \mu \mathrm{M}\right)$ and chloroquine $\left(\mathrm{EC}_{50}=1.14 \mu \mathrm{M}\right)$, respectively.

\section{Introduction}

Currently, there is an increasing need to develop broad-spectrum antimicrobial agents that can inactivate human pathogens, such as bacteria and viruses. Moreover, rapid development of antimicrobial resistance in microorganisms has propelled the development of targeted drugs. The most recent trigger is the fear of a future pandemic caused by poorly studied novel virulent strains, such as the severe acute respiratory syndrome coronavirus 2 (SARS-CoV-2).

\section{Background information on SARS-CoV-2}

The ongoing COVID-19 pandemic caused by SARS-CoV-2 [1] has created global havoc within a few months of its emergence. Medically controlling the rapid viral spread by utilizing specific antivirals and vaccines is expensive and time consuming and compromises on the safety and efficacy of the treatment. Thus, an alternative approach is to test compounds that have already been proven to be effective and safe against SARS-CoV-2. In this study, Camostat mesylate (a 35-year-old Japanese drug), avigan (another Japanese drug), and remdesivir (Gilead Science Inc.) were evaluated for this purpose [2].

The SARS-CoV-2 virus enters a host cell by interacting with the transmembrane protease serine 2 (TMPRSS2) [3], a serine protease, and the angiotensin-converting enzyme 2 (ACE2) present on the host 
cell [4]. Thus, inhibiting TMPRSS2 is the key to blocking the virus from binding to ACE2, hindering the mechanism underlying its entry into the host cell.

The serine protease TMPRSS2 is responsible for priming the spike proteins of SARS-CoV and Middle East respiratory syndrome-related coronavirus. Studies have demonstrated that the TMPRSS2 inhibitor Camostat mesylate (CM) inhibits SARS-CoV-2 in a mouse model [5,6]. Furthermore, Hoffmann et al. [7] determined that SARS-CoV-2 requires TMPRSS2 for entry into host cells, as they demonstrated that CM blocked viral entry into the lungs. However, to date, there are no clinical data on the use of CM to treat COVID-19 patients.

The other host receptor essential viral entry into the host cells is the transmembrane protein ACE2, as the spike (S) protein on the exterior of SARS-CoV-2 viral envelope binds to ACE2. However, as ACE2 also regulates blood pressure and blood volume, blocking ACE2 is detrimental to the health of the host. Thus, an ideal approach to inhibit viral entry is to inhibit TMPRSS2.

\section{Lipids and viruses}

The viral lipid envelope is crucial for both viral stability and infection. For example, substances, such as phospholipases, organic solvents, and surfactants (e.g. soaps), that affect this envelope have been demonstrated to affect viral infectivity as well [8]. Thus, disintegrating this envelope can prevent transmission of the virus to a new host. Furthermore, active ingredients in cleaning agents, wipes, and tissues target the viral lipid envelope to render the virions nonviable. Snipes et al. [9] reported that saturated alcohols with chain lengths ranging from 10-14 carbons can inactivate viruses. They also established that inactivation of these enveloped viruses using lipids varied greatly depending on both the nature of the lipid and the type of the virus. Hilmarsson et al. [10-12] studied the virucidal effects of medium- and long-chain-fatty alcohols (8-18 carbons) and that of corresponding lipids against the herpes simplex viruses (HSV-1) and (HSV-2), respiratory syncytial virus, human parainfluenza virus type 2 , and enveloped viruses at various concentrations, timepoints, and $\mathrm{pH}$ levels. They found that after a $10-$ minute incubation at $37{ }^{\circ} \mathrm{C}, 14$ of the tested lipids caused a significant reduction (100000-fold or more) in HSV titer at $10 \mathrm{mM}$ concentrations. Additionally, a pH of 4.2 caused a more rapid inactivation of HSV- 1 in one minute than higher $\mathrm{pH}$ values $(\mathrm{pH} 7)$ did. Thus, it can be deduced that these long-chain alcohols possibly penetrate the viral envelope hydrophobically, making the envelope permeable to small molecules and thus inactivating the virus. However, the degree of penetration into the lipid membranes is based on the chain length of the alcohols compared with the thickness of the membrane [13].

Metadichol ${ }^{\circledR}$ is a lipid formulation of long-chain alcohols, containing C26, C28 (more than 80\%), and C30 [14]. Previous studies have demonstrated that Metadichol® inhibits viruses both in vitro and in vivo [1517]. Thus, in this study, we evaluated the inhibitory effect of Metadichol, a Nano emulsion, against ACE2, angiotensin-converting enzyme (ACE), and TMPRSS2 and tested its efficacy in a SARS-CoV-2 antiviral assay. 


\section{Materials And Methods}

All assays were conducted on a fee-for-service contract basis and outsourced to bioanalytical testing companies worldwide. The SARS-CoV-2 antiviral assays were performed in a biosafety level 3 facility at the Anti-viral Research Institute Utah State University, Logan, Utah USA. Other assays were performed in the Infectious Disease Research Facility at the Southern Research Institute in Frederick, Maryland, USA and IBT Bio-Services in Rockville, Maryland, USA. Additionally, the ACE2, ACE, and TMPRSS2 assays were carried out by Skanda Life Sciences Pvt. Ltd. in Bangalore, India.

\section{Antiviral assay}

Metadichol was serially diluted into eight half-log dilutions in a test medium (minimum essential media supplemented with $2 \%$ fetal bovine serum and $50 \mu \mathrm{g} / \mathrm{mL}$ of gentamicin) to obtain a high starting test concentration of $100 \mu \mathrm{g} / \mathrm{mls}$ Each dilution was added to five wells in a 96-well plate containing Caco-2 cells (80-100\% confluency). Subsequently, three wells of each dilution were inoculated with SARS-CoV-2, whereas the other two wells were uninoculated (as cytotoxicity controls). Additionally, six wells were inoculated with the virus but left untreated (viral controls), whereas six wells were uninoculated and untreated (cell controls). For the next five days, the lowest possible multiplicity of infection value for SARS-CoV-2 that led to $>80 \%$ cytopathic effect (CPE) in the host cells were evaluated. The SARS-CoV-2specific protease inhibitor M128533 was also tested in parallel as a positive control. The plates were incubated at $37 \pm 2{ }^{\circ} \mathrm{C}$ in $5 \% \mathrm{CO}_{2}$. Once the viral control cells exhibited maximum $\mathrm{CPE}$ on the third day post-infection, neutral red dye was added in the wells for approximately $120 \pm 15 \mathrm{~min}$. The dye in the supernatant was removed and the wells were rinsed with PBS. Subsequently, the incorporated dye was extracted using a 50:50 ratio of Sorensen citrate buffer to ethanol for $>30 \mathrm{~min}$. The optical densities were measured at $540 \mathrm{~nm}$ using a spectrophotometer. These values (in percentage) were normalized with that of the cell controls and the cytotoxic concentration of a compound that caused $50 \%$ cell death $\left(\mathrm{CC}_{50}\right)$ in the absence of the virus was calculated by using regression analysis. The selective index (SI) was obtained by dividing the $\mathrm{CC}_{50}$ value with the $\mathrm{EC}_{90}$ value. These results are listed in Table 1.

To perform the viral yield reduction assay, the supernatant was collected from wells corresponding to each concentration of Metadichol on day three post-infection. Following this, neutral red was added to the wells ( 3 wells of each concentration pooled) and the viral titer was measured. This was done by conducting a standard endpoint dilution $\mathrm{CCID}_{50}$ assay in Vero 76 cells and by calculating the viral titer using the Reed-Muench (1938) equation[18]. The concentration of a compound that reduced the viral yield by one $\log _{10}$ was calculated by using regression analysis $\left(\mathrm{EC}_{90}\right)$.

As shown in Table 2, the viral reduction assay did not follow a typical dose-response curve, as viral reduction was observed at $0.3 \mu \mathrm{g} / \mathrm{ml}$ and $3.2 \mu \mathrm{g} / \mathrm{ml}$ but no reduction was observed at $1 \mu \mathrm{g} / \mathrm{mL}$. Thus, it was assumed that the viral breakthrough at $1 \mu \mathrm{g} / \mathrm{ml}$ was an outlier. The calculated SI was 20 (Table 1), indicating an $\mathrm{EC}_{90}$ of $0.15 \mu \mathrm{g} / \mathrm{ml}$. 
Similarly, the experimental results for other viruses carried out by various laboratories in Vero cells are depicted in Tables 3, 4. Table 5 is list of all viruses inhibited by Metadichol ${ }^{\circledR}$.

\section{TMPRSS2 inhibition assay}

The TMPRSS2 protein was purified from LNCaP cells (obtained from American Tissue Culture Collection) and used as an enzyme source. A reaction mixture containing the purified TMPRSS2 protease in trisbuffered saline was prepared with or without the test samples or protease inhibitor (concentrations ranged from $1.56-100 \mathrm{ng} / \mathrm{mL}$ for both). The reaction mixture was incubated for $10 \mathrm{~min}$ at $37^{\circ} \mathrm{C}$. Subsequently, $1 \mu \mathrm{L}$ of $10 \mathrm{mM}$ of the fluorogenic trypsin substrate Cbz-Gly-Gly-Arg-AMC was added to the reaction mixture and incubated for $2 \mathrm{~min}$ at $37^{\circ} \mathrm{C}$. The kinetic fluorescence values were measured at an excitation wavelength of $383 \mathrm{~nm}$ and an emission wavelength of $455 \mathrm{~nm}$ at 10 minutes using Spectra Max i3X (Molecular Devices, San Jose, CA USA). The inhibitory effects of the test samples were determined by calculating the changes in their RFU (Relative Fluorescence Units). Moreover, CM (Camostat Mesylate (Sourced from Cayman Chemicals) was used at concentrations ranging from 1.56$100 \mathrm{~nm}$ (nano molar) was used as a positive control for TMPRSS2 inhibition.

\section{ACE2 inhibition assay}

The ACE2 Inhibitor Screening Assay Kit, catalog no. 79923 (BPS Biosciences, San Diego, CA, USA), was used to measure the exopeptidase activity of ACE2 and to evaluate the inhibitory effect of Metadichol and DX600 (control) on ACE2. The inhibitory activities of these compounds were measured by the intensity of the fluorescence emitted upon cleavage of the chromogenic substrate.

Enzyme (ACE2) stocks were prepared using the supplied kit. Subsequently, $20 \mu \mathrm{L}$ of the enzyme solution $(0.5 \mathrm{ng} / \mu \mathrm{l})$ was added to all the wells designated for the assay. The potent ACE2 inhibitor DX600 was used as a positive control for ACE2 inhibition at concentrations ranging from $0.0156-1 \mu \mathrm{g} / \mathrm{ml}$. Additionally, the inhibitory effects of the test samples were tested at concentrations ranging from $0.125-$ $40 \mu \mathrm{g} / \mathrm{ml}$. Thereafter, $5 \mu \mathrm{L}$ of the inhibitors were added to the wells containing the enzyme solution. The resultant reaction mixture was incubated at room temperature for $5 \mathrm{~min}$. Post incubation, $25 \mu \mathrm{L}$ of the ACE2 substrate was added to the wells and incubated for $1 \mathrm{~h}$ at room temperature. The RFU upon the cleavage of the substrate was measured at an excitation wavelength of $555 \mathrm{~nm}$ and an emission wavelength of $585 \mathrm{~nm}$ using the SpectraMax i3x (Molecular Devices). The IC ${ }_{50}$ values were calculated based on these measurements.

\section{ACE inhibition assay}

The inhibitory activity of the test samples against ACE was assessed using the Angiotensin I converting Enzyme (ACE) Fluorometric Activity Assay Kit (Cat. No. CS0002) as per the manufacturer's instructions, with slight modifications. 


\section{Sample Preparation}

1. The ACE positive control was used as the main enzyme source for the assay, and a working stock solution was prepared by diluting ACE 250 -fold in the assay buffer.

2. Sample stock solutions of $5 \mathrm{mg} / \mathrm{mL}$ were used to obtain various desired concentrations of the test samples.

3. The final volumes of all the test samples were $25 \mu \mathrm{L}(2 \times$ concentration)

Assay procedure

All reagents were equilibrated at $37^{\circ} \mathrm{C}$ for 5 min before performing the assay. Freshly prepared ACE enzyme solution $(25 \mu \mathrm{L})$ was added to test sample solutions ( $25 \mu \mathrm{L}$ of different $2 \times$ concentrations) in 96well flat-bottom black plates. This reaction mixture was gently mixed using a pipette and incubated for 5 min at room temperature. The reaction was initiated by adding $50 \mu \mathrm{L}$ of 100 -fold diluted substrate to a final reaction volume of $100 \mu \mathrm{L}$ and incubated for $5 \mathrm{~min}$ at room temperature. Subsequently, the fluorescence intensity of each reaction was measured at an excitation wavelength of $320 \mathrm{~nm}$ and an emission wavelength of $405 \mathrm{~nm}$.

Captopril was used as a positive control at various concentrations.

\section{Results And Discussion}

As summarized in Table 1 and 2, Metadichol had a direct antiviral effect against SARS-CoV-2 in Caco-2 cells at an $\mathrm{EC}_{90}$ of $0.15 \mu \mathrm{g} / \mathrm{mL}(0.00026 \mu \mathrm{M})$. Thus, this demonstrated that Metadichol was 2000-fold more effective as an antiviral agent than Remdesivir $\left(\mathrm{EC}_{50} 0.77 \mu \mathrm{M}\right)$ and 3000 -fold more potent than hydroxychloroquine phosphate $\left(\mathrm{EC}_{50} 1.13 \mu \mathrm{M}\right)$ [19].

A previously published work [15] of antiviral data against other viruses is presented in Tables 3 and 4 . The raw data depict the cytotoxicity of Metadichol in the absence of a virus in Vero cells measured using a neutral red assay. No viral CPE value was reported when the "cytotoxicity" was $>75 \%$. These results may suggest that Metadichol is cytotoxic to cells at concentrations above $5 \mu \mathrm{g} / \mathrm{ml}$. However, Metadichol is not toxic, as the $L D_{50}$ value is $5000 \mathrm{mg} / \mathrm{kg}$ in a rats [20-22]. It is likely that Metadichol mimics characteristics of soaps and disrupts the lipid membrane of virus at higher concentrations, whereas it neutralizes the virus by a different mechanism at lower concentrations. Additionally, Meadichol selectively targets cancer cells in Caco-2 cells. [23] and cancer cell lines Mia-Paca, Colo 205, and Panc1 where Metadichol was cytotoxic to all these cell lines above $1 \mu \mathrm{g} / \mathrm{ml}$. It is selectively cytotoxic at $10 \mu \mathrm{g} / \mathrm{mL}$ in leukemia cells [24]. 
Metadichol also inhibited TMPRSS2 (Table 6 and Figures 1 and 2) and was 270-fold more potent than CM [25]. Nevertheless, for all practical purposes, it does not inhibit ACE2 (Table 7 and Figures 3 and 4). and inhibits TMPRSS2 which is needed for the virus to bind to ACE 2. Thus, the reported results provide a gateway to effective and safe therapies for COVID-19 patients. On the other hand, Metadichol did inhibit ACE (Table 8 and Figures 5 and 6). Inhibition of ACE, a blood pressure regulator, is crucial to mitigate COVID-19 infections, as Guan et al [26] validated that the single highest risk factor in infections is hypertension in $15 \%$ of the 1099 COVID-19 patients that participated in the study.

\section{Vitamin D and the SARS-CoV-2 infection}

An uncontrolled inflammatory response to SARS-CoV-2 is the major cause of disease severity and death in COVID-19 patients [27]. This response is associated with high levels of circulating cytokines, tumor necrosis factors (TNF), monocyte chemoattractant protein 1

(CCL2), C-reactive protein (CRP), and ferritin. Notably, Metadichol [14] inhibits CCL2 (also known as MCP1), TNF, NF-KB, and CRP, which is a surrogate marker of cytokine storms [28] and all these cytokines are increased in patients with vitamin $\mathrm{D}$ deficiency.

Vitamin D3 is produced in the skin upon exposure to ultraviolet $B$ radiation via the generation of 7dehydrocholesterol followed by a thermal reaction. It is converted to $25(\mathrm{OH}) \mathrm{D}$ in the liver and subsequently to 1,25(OH)2D (calcitriol) in the kidneys, where calcitriol binds to the nuclear vitamin $D$ receptor (VDR). This receptor is a DNA-binding protein that interacts with regulatory sequences near target genes and recruit's chromatin active complexes that genetically and epigenetically regulate the gene transcripts [29]. Vitamin $D$ reduces the risk of infections by mechanisms that induce Cathelicidin and defensins [30], resulting in lowered replication rates of viruses and reduced concentrations of proinflammatory cytokines [31]. For instance, supplementation with $4000 \mathrm{IU} / \mathrm{d}$ of vitamin D decreased the dengue virus infection [32]. Inflammatory cytokine levels increase in viral and bacterial infections, as is observed in COVID-19 patients. However, vitamin D can reduce the production of pro-inflammatory cytokines, such as TNF and interferon (IFN), secreted by Thelper type 1 (Th1) cells [33], and thus is a modulator of adaptive immunity [34]. For example, it primarily suppresses Th1-mediated immune responses by repressing the production of the inflammatory cytokines interleukin (IL)-2 and IFN-gamma [35]. Additionally, 1,25(OH)2D3 promotes cytokine production by Thelper type 2 (Th2) cells and enhances the indirect suppression of Th1 cells by promoting the actions of a multitude of cell types [36]. It also induces the expression of T regulatory cells, thereby inhibiting inflammatory processes [37]. Remarkably, Metadichol is an inverse agonist (protean agonist) [14] of VDR, i.e., it binds to VDR at the same site as calcitriol but has different properties. It is the only known inverse agonist of VDR in medical literature.

\section{Telomerase and viral infections}


Viral infection places substantial strain on the body. Notably, CD8+ T cells mediate adaptive immunity [38] to protect the body from microbial invaders. However, they can easily reach their Hayflick limit due to progressive telomere shortening [39]; this is more likely if the telomeres are already short. Thus, infections can enormously strain the immune cells to replicate. Naive T and B cells $[40,41]$ are particularly important for protection against new pathogens, such as SARS-CoV-2. Thus, the quantity of these cells is crucial to initiate an effective immune response. In this regard, 1 pico $\mathrm{gram} / \mathrm{ml}$ of Metadichol has been found to increase h-TERT (telomerase) expression by 16-fold [42].

\section{Aryl hydrocarbon receptor and viral infections}

One of the major complications observed in infected COVID-19 patients is respiratory failure. A possible underlying mechanism is the activation of the aryl hydrocarbon receptor (AHR) during COVID-19 that can impact antiviral immunity and the function of repair-associated lung cells [43]. Thus, the AHR signaling pathway can dampen the immune response against SARS-CoV-2 [44]. Remarkably, studies have reported that while AHR signaling is required for SARS-CoV-2 replication, upregulation of this pathway may be deleterious to the virus. This is because AHR limits activation and interferes with multiple antiviral immune mechanisms, including IFN-I production and intrinsic immunity. [45] which suggests that AHR signaling constrains IFN type I-mediated innate antiviral defense and the need to block constitutive AHR activity. Of note, only an inverse agonist can hinder this activity. Previously, we have shown that Metadichol $\circledast$ binds to AHR as an inverse/protean agonist [46] and thus reduces complications attributed to uncontrolled inflammation and cytokine storms.

\section{Vitamin C and viral infections}

There is a need to boost the innate and adaptive immunity of a person in response to infectious diseases. Micronutrients that have been identified to robustly promote immunity are vitamins $C$ and $D$. Vitamin $C$ is essential for a healthy and functional host defense, and its pharmacological application has been demonstrated to enhance immune function [47]. It exhibits antiviral properties that inhibit the replication of HSV-1, poliovirus type 1, influenza virus type A and B [48], and rabies virus in vitro [49].

Vitamin C deficiency reduces cellular [50-54] and humoral immune responses. Treatment of healthy subjects promotes and enhances natural killer (NK) cell activities [55], underlining the immunological importance of vitamin C $[56,57]$. This validates its crucial role in various aspects of immune cell functions, such as immune cell proliferation and differentiation, in addition to its anti-inflammatory properties. Vitamin $\mathrm{C}$ is also required as a cofactor for the optimal activity of newly characterized hydroxylase enzymes, which regulate the activity, gene transcription, and signaling of hypoxia-inducible factors in immune cells [58-60]. Of note, studies have demonstrated that Metadichol administration increases the endogenous vitamin $\mathrm{C}$ levels by recycling it to levels that are not achieved by oral intake, and these levels bring about changes in improving diverse biomarkers [61-63]. 


\section{Gene cluster network analysis in COVID-19 infections}

The present drug discovery paradigm is based on the idea of one gene, one target, and one disease. Nevertheless, it has become clear that it is difficult to achieve single target specificity. Thus, it is more likely that targeting multiple genes rather than single genes can help block multiple paths of disease progression $[64,65]$. Gene network analysis provides a minimum set of target genes that form the basis of a disease. This cluster of genes modulates gene pathways and biological networks involved in the disease. The database www.ctdbase.org [66] was used to curate genes that were relevant to COVID-19 (Table 9). Table 10 lists the curated genes and the diseases that they are involved in.

The 13 identified genes were screened and categorized in set of five genes: TNF, CCL2, ACE2, TMPRSS2, and $A G T$, which belongs to the renin-angiotensin system network (Figure 7). Metadichol modulated all these genes by binding to VDR. A similar analysis of these genes demonstrated that they were clustered closely in diseases and had a highly significant $p$-value $<10^{-6}$. Furthermore, a network of these five closely related genes was generated using www.innatedb.org [67] (Figure 8). This analysis integrates known gene interactions and pathways curated from major public databases. The highlighted ones in yellow are SIRT1, androgen receptor (AR), and FOS.

Glinsky [68] suggested that vitamin D is a potential mitigation agent that prevents SARS-CoV-2 entry. Notably Metadichol binds to VDR which controls the expression of FOS [69]. Moreover, VDR regulates SIRT1 [70] in viral infections [71]. Subsequently, SIRT1 regulates the expression of AR [72] that in turn regulates the expression of TMPRSS2. Figure 9, generated using PACO [73], presents the gene network and corresponding regulatory relationships. The analysis revealed that VDR also regulated FOS expression, whereas FOS regulated AGT expression and , AGT mediated the expression levels of AGTR1 and ACE.

Wambier and Goren [74] suggested that the SARS-CoV-2 infection is likely to be androgen-mediated as AR controls expression of TMPRSS2.The first step that occurs in the COVID-19 infection is the priming of the SARS-CoV-2 spike proteins by TMPRSS2; these proteins cleave ACE2 to augment viral entry into the host cells. However, Metadichol can completely inhibit this key priming step.

Proteases such as Furin [75] and Adam-17 have been reported to activate the spike protein in vitro, enabling viral spread and pathogenesis in infected hosts. Notably, VDR controls Furin expression via its interaction with SRC (Proto-oncogene tyrosine-protein kinase Src)

[76]. On the other hand, Adam-17 is regulated via CEPBP (CCAAT Enhancer Binding Protein Beta) [77,78], which is involved in the regulation of genes involved in immune and inflammatory responses. Recently, Ulrich and Pillat [79] proposed that CD147, like ACE2, is another host receptor used by the virus to enter host cells. CD147 is a known receptor [80] of Plasmodium falciparum, the parasite that causes malaria in humans. Remarkably, a previous study has demonstrated that Metadichol [14](US patent 9,006,292) inhibits malarial parasites. 


\section{Controlling cytokine storms}

A cytokine storm develops when an initial immune response induces the production of cytokines. It is initiated in the host body in response to SARS-CoV-2 and leads to inflammation and increases the secretion of the pro-inflammatory cytokines

Figure 10 depicts the cytokine relationship network generated in this study using PACO. Cytokines can activate $T$ cells and cause tissue damage and infection in the lungs. Remarkably, Metadichol is an in vivo inhibitor [14] (US patent 8,722,093) of TNF alpha. The endocytosis of ACE2 with SARS-CoV-2 results in a reduction in ACE2 on cell surfaces, thus increasing serum angiotensin II levels [81]. Angiotensin II is a vasoconstrictor and pro-inflammatory cytokine (Figure 11) that acts via AT1R [82]. The angiotensin IIAT1R axis leads to a pro-inflammatory state [83] in the host, causing infections by activating NF-KB and increasing IL-6 levels in multiple inflammatory and autoimmune diseases [84].

Thus, the dysregulation of angiotensin II downstream of ACE2 leads to cytokine release in COVID-19 patients. This increases TNF levels that in-turn elevate IL-6, CCl2, and CRP levels. Therefore, cytokine storms [85] result in ARDS. However, Metadichol is an ACE inhibitor that blocks the angiotensin I and II pathways, promoting an anti-inflammatory state.

\section{Clinical}

A pilot study conducted by a third party, Kasturaba Hospital in Mumbai, India, on 30 COVID-19 patients with minor symptoms revealed that Metadichol treatment ( $20 \mathrm{mg} /$ day) eliminated by Rt-PCR test the virus in $75 \%$ of patients after four days of treatment (Supplements). To validate this finding, a larger study consisting of a Metadichol treatment group and control groups with only standard care provided to the participants were initiated. We hope to communicate these results in the future.

\section{Summary And Conclusions}

Metadichol inhibits the entry of SARS-CoV-2 into host cells by inhibiting TMPRSS2, thus allowing ACE2 to play a critical role in the renin-angiotensin pathway. In addition, it enhances the antiviral response of the host by increasing the innate and adaptive immune responses through the vitamin $D$ pathway and by endogenously increasing the vitamin $\mathrm{C}$ levels. In addition, telomerase activity also plays a key role in maintaining the levels of naive $T$ and $B$ cells required to fight infections. Metadichol modulates cytokine storms, as it is an inhibitor of TNF, ICAM1, and CCL2 that play a key role in generating cytokine storms. Metadichol also regulates COVID-19-associated co-morbidities [86,87], such as hypertension and diabetes $[88,89,90]$. Thus, Metadichol has the potential to improve the long-term prognosis of the affected patient population. Metadichol acts on multiple genes and has over 2000 unique gene interactions, thereby resulting in a network that brings about homeostasis and prevents SARS-CoV-2 infections. 
Metadichol is a safe, non-cytotoxic product LD 50 is greater than $\mathbf{5 0 0 0}$ mgs per kilo in rat studies. It is made from renewable sources like sugar cane or rice. It has been commercially available for the last six years and has no reported side effects. Thus, Metadichol can potentially be used as an immune modulator to prevent future occurrences of SARS-CoV-2 and possibly other predicted infections, facilitating a rapid return to normal social and economic human activities worldwide.

\section{Declarations}

\section{Data availability statement}

\section{Conflicts of Interests}

The author declares that there is no conflict of interest regarding the publication of this paper.

\section{Funding statement}

\section{Acknowledgements}

We thank Dr. Michele Muller for Sferalp S. A., Switzerland for helpful discussions. This paper has been submitted as a preprint and is available in the manuscript and has been submitted and published as a preprint and can be accessed at htttps://www.researchsquare.com/article/rs-34021/v8.

\section{References}

1. J. S. Morse, T. Lalonde, S. Xu et al., "Learning from the past: possible urgent prevention and treatment options for severe acute respiratory infections caused by 2019-nCoV," Chembiochem: $A$ European Journal of Chemical Biology, vol. 21, no. 5, pp. 730-738, 2020.

2. G. Li and E. De Clercq, "Therapeutic options for the 2019 novel coronavirus (2019-nCoV)," Nature Reviews Drug Discovery, vol. 19, no. 3, pp. 149-150, 2020.

3. J. Jankun, "COVID-19 pandemic; transmembrane protease serine 2 (TMPRSS2) inhibitors as potential drugs," Translation: The University of Toledo Journal of Medical Sciences, vol. 7, pp. 1-5, 2020.

4. I. Hamming, M. E. Cooper, B. L. Haagmans et al., "The emerging role of ACE2 in physiology and disease," The Journal of Pathology, vol. 212, no. 1, pp. 1-11, 2007.

5. A. A. Rabaan, "Middle East respiratory syndrome coronavirus: five years later," Expert Review of Respiratory Medicine, vol. 11, no. 11, pp. 901-912, 2017.

6. Y. Zhou, P. Vedantham, K. Lu et al., "Protease inhibitors targeting coronavirus and filovirus entry," Antiviral Research, vol. 116, pp. 76-84, 2015. 
7. M. Hoffmann, H. Kleine-Weber, S. Schroeder et al., "SARS- CoV-2 cell entry depends on ACE2 and TMPRSS2 and is blocked by a clinically proven protease inhibitor," Cell, vol. 181, no. 2, pp. 271-280, 2020.

8. J. S. Greatorex, R. F. Page, M. D. Curran et al., "Effectiveness of common household cleaning agents in reducing the viability of human influenza A/H1N1," PLoS One, vol. 5, no. 2, e8987, 2010.

9. W. Snipes, S. Person, G. Keller et al., "Inactivation of lipid-containing viruses by long-chain alcohols," Antimicrobial Agents and Chemotherapy, vol. 11, no. 1, pp. 98-104, 1977.

10. H. Hilmarsson, T. Kristmundsdottir and H. Thormar, "Virucidal activities of medium- and long-chain fatty alcohols, fatty acids and monoglycerides against herpes simplex virus types 1 and 2 : comparison at different pH levels," Apmis, vol. 113, no. 1, pp. 58-65, 2005.

11. H. Hilmarsson, L. V. Larusson and H. Thormar, "Virucidal effect of lipids on visna virus, a lentivirus related to HIV," Archives of Virology, vol. 151, no, 6, pp. 1217-1224, 2006.

12. H. Hilmarsson, B. S. Traustason, T. Kristmundsdóttir et al., "Virucidal activities of medium- and longchain fatty alcohols and lipids against respiratory syncytial virus and parainfluenza virus type 2: comparison at different pH levels," Archives of Virology, vol. 152, no. 12, pp. 2225-2236, 2007.

13. C. E. Isaacs, K. Kims and H. Thormar, "Inactivation of enveloped viruses in human bodily fluids by purified lipids," Annals of the New York Academy Sciences, vol. 724, pp. 457-464, 1994.

14. Raghavan, P. R. U.S patents 8,722, 094 (2014); 9,034,383 (2015); 9,006,292(2015).

15. P. R. Raghavan, "In vitro inhibition of zika virus by Metadichol®, a novel nano emulsion lipid," Journal of Immunological Techniques in Infectious Diseases, vol. 5, no. 4, pp. 2-6, 2016.

16. P. R. Raghavan, "Inhibition of Dengue and other enveloped viruses by Metadichol®, a novel Nanoemulsion Lipid," Journal of the Science of Healing Outcomes, vol. 8, pp. 19-25, 2016.

17. P.R Raghavan, "Inhibition of viruses by Metadichol®: A novel nano emulsion lipid," Pediatric Infectious Diseases, vol. 2, no. 35, pp. 35, 2017.

18. Reed LJ, Muench H. A simple method of estimating fifty-percent endpoints. Am J Hyg. 1938;27:493497

19. M. Wang, R. Cao, L. Zhang et al., "Remdesivir and chloroquine effectively inhibit the recently emerged novel coronavirus (2019-nCoV) in vitro," Cell Research, vol. 30, no. 3, pp. 269-270, 2020.

20. C. L. Alemáns, R. Más, C. Hernández et al., "A 12-month study of policosanol oral toxicity in Sprague Dawley rats," Toxicology Letters, vol. 70, no. 1, pp. 77-87, 1994.

21. C. L. Alemán, R. M. Ferreiro, M. N. Puig et al., "Carcinogenicity of policosanol in Sprague Dawley rats: a 24 month study," Teratogenesis, Carcinogenesis, and Mutagenesis, vol. 14, no. 15, pp. 239-249, 1994.

22. C. L. Alemán, M. N. Puig, E. C. Elias et al., "Carcinogenicity of policosanol in mice: an 18-month study," Food and Chemical Toxicology, vol. 33, no. 7, pp. 573-578, 1995.

23. P. R. Raghavan, "Metadichol ${ }^{\circledR}$ a novel agonist of the anti-aging klotho gene in cancer cell lines," Journal of Cancer Science \& Therapy, vol. 10, pp. 351-357, 2018. 
24. P. R. Raghavan unpublished results.

25. Y. Uno, "Camostat mesilate therapy for COVID-19," Internal and Emergency Medicine, vol. 15, no. 8, pp. 1577-1578, 2020.

26. W. J. Guan, Z. Y. Ni, Y. Hu et al., "Clinical characteristics of coronavirus disease 2019 in China," New England Journal of Medicine, vol. 382, no. 18, pp. 1708-1720, 2020.

27. M. Merad and J. C. Martin, "Pathological inflammation in patients with COVID-19: a key role for monocytes and macrophages," Nature Reviews Immunology, vol. 20, no. 6, pp. 355-362, 2020.

28. A. Daneshkhah, V. Agrawal, A. Eshein et al., "The possible role of Vitamin D in suppressing cytokine storm and associated mortality in COVID-19 patients," MedRxiv, vol. 4, Article ID: 20058578, 2020.

29. J. W. Pike and S. Christakos, "Biology and mechanisms of action of the Vitamin D hormone," Endocrinology \& Metabolism Clinics, vol. 46, no. 4, pp. 815-843, 2017.

30. P. T. Liu, M. Schenk, V. P. Walker et al., "Convergence of IL-1beta and VDR activation pathways in human TLR2/1-induced antimicrobial responses," PLoS One, vol. 4, no. 6, e5810, 2009.

31. T. T. Wang, F. P. Nestel, V. Bourdeau et al., "Cutting edge: 1,25-dihydroxyvitamin D3 is a direct inducer of antimicrobial peptide gene expression," The Journal of Immunology, vol. 173, no. 5, pp. 29092912, 2004.

32. J. Martínez-Moreno, J. C. Hernandez and S. Urcuqui-Inchima, "Effect of high doses of vitamin D supplementation on dengue virus replication, Toll-like receptor expression, and cytokine profiles on dendritic cells," Molecular and Cellular Biochemistry, vol. 464, no. 1, pp. 169-180, 2020.

33. C. G. Spilianakis, G. R. Lee and R. A. Flavell, "Twisting the Th1/Th2 immune response via the retinoid $X$ receptor: lessons from a genetic approach," European Journal of Immunology, vol. 35, no. 12, pp. 3400-3404, 2005.

34. R. Wei and S. Christakos, "Mechanisms underlying the regulation of innate and adaptive immunity by Vitamin D," Nutrients, vol. 7, no. 10, pp. 8251-8260, 2015.

35. M. T., Cantorna, L. Snyder, Y. D. Lin et al., "Vitamin D and 1,25(OH) 2D regulation of T cells," Nutrients, vol. 7, no. 4, pp. 3011-3021, 2015.

36. M. T. Cantorna, "Mechanisms underlying the effect of vitamin D on the immune system," Proceedings of the Nutrition Society, vol. 69, no. 3, pp. 286-289, 2010.

37. J. M. Lemire, J. S. Adams, V. Kermani-Arab et al., "1,25-Dihydroxyvitamin D3 suppresses human T helper/inducer lymphocyte activity in vitro," The Journal of Immunology, vol. 134, no. 5, pp. 3032$3035,1985$.

38. C. Huang, Y. Wang, X. Li et al., "Clinical features of patients infected with 2019 novel coronavirus in Wuhan, China," The Lancet, vol. 395, no. 10223, pp. 497-506, 2020.

39. D. Wang, B. Hu, C. Hu et al., "Clinical characteristics of 138 hospitalized patients with 2019 novel coronavirus-infected pneumonia in Wuhan, China," JAMA, vol. 323, no. 11, pp. 1061-1069, 2020.

40. N. P. Weng, "Telomere and adaptive immunity," Mechanisms of Ageing and Development, vol. 129, no. $1-2$, pp. 60-66, 2008. 
41. R. J. Hodes, K. S. Hathcock and N. P. Weng, "Telomeres in T and B cells," Nature Reviews Immunology, vol. 2, no. 9, pp. 699-706, 2002.

42. Raghavan PR (2019) The Quest for Immortality: Introducing Metadichol® a Novel Telomerase Activator. Stem Cell Res Ther 9: 446. doi: 10.4172/2157-7633.1000446

43. M. Poppe, S. Wittig, L. Jurida et al., "The NF-kB-dependent and -independent transcriptome and chromatin landscapes of human coronavirus 229E-infected cells," PLoS Pathogens, vol. 13, no. 3, e1006286, 2017.

44. F. Giovannoni, I. Bosch, C. M. Polonio et al., "AHR is a Zika virus host factor and a candidate target for antiviral therapy," Nature Neuroscience, vol. 23, no. 8, pp. 729-740, 2019.

45. T. Yamada, H. Horimoto, T. Kameyama et al., "Constitutive aryl hydrocarbon receptor signaling constrains type I interferon-mediated antiviral innate defense," Nature Immunology, vol. 17, no. 6, pp. 687-694, 2016.

46. P. R. Raghavan, "Metadichol ${ }^{\circledR}$. A novel inverse agonist of aryl hydrocarbon receptor (AHR) and NRF2 inhibitor," Journal of Cancer Science and Therapy, vol. 9, no. 9, pp 661-668, 2017.

47. G. Heuser and A. Vojdani, "Enhancement of natural killer cell activity and T and B cell function by buffered Vitamin $\mathrm{C}$ in patients exposed to toxic chemicals: the role of protein kinase-C," Immunopharmacology and Immunotoxicology, vol. 19, no. 3, pp. 291-312, 1997.

48. A. Furuya, M. Uozaki, H. Yamasaki et al., "Antiviral effects of ascorbic and dehydroascorbic acids in vitro," International Journal of Molecular Medicine, vol. 22, no. 4, pp. 541-545, 2008.

49. H. Kim, M. Jang, Y. Kim et al., "Red ginseng and vitamin $C$ increase immune cell activity and decrease lung inflammation induced by influenza A virus/H1N1 infection," Journal of Pharmacy and Pharmacology, vol. 68, no. 3, pp. 406-420, 2016.

50. S. N. Madhusudana, R. Shamsundar and S. Seetharaman, "In vitro inactivation of the rabies virus by ascorbic acid," International Journal of Infectious Diseases, vol. 8, no. 1, pp. 21-25, 2004.

51. O. Alvares, L. C. Altman, S. Springmeyer, "The effect of subclinical ascorbate deficiency on periodontal health in nonhuman primates," Journal of Periodontal Research, vol. 16, no. 6, pp. 628636, 1981.

52. M. C. Goldschmidt, W. J. Masin, L. R. Brown, "The effect of ascorbic acid deficiency on leukocyte phagocytosis and killing of actinomyces viscosus," International Journal for Vitamin and Nutrition research. Internationale Zeitschrift fur Vitamin- und Ernahrungsforschung. Journal International de Vitaminologie et de Nutrition, vol. 58, no. 3, pp. 326-334, 1988.

53. E. S. Wintergerst, S. Maggini and D. H. Hornig, "Immune-enhancing role of Vitamin C and zinc and effect on clinical conditions," Annals of Nutrition and Metabolism, vol. 50, no. 2, pp. 85-94, 2006.

54. A. Woo, J. H. Kim, Y. J. Jeong et al., "Vitamin $\mathrm{C}$ acts indirectly to modulate isotype switching in mouse B cells," Anatomy \& Cell Biology, vol. 43, no. 1, pp. 25-35, 2010.

55. A. C. Carr and S. Maggini, "Vitamin C and immune function," Nutrients, vol. 9, no. 11, pp. 1211, 2017. 
56. P. Washko, D. Rotrosen and M. Levine, "Ascorbic acid in human neutrophils," The American Journal of Clinal Nutrition, vol. 54, no. 6, pp. 1221S-1227S, 1991.

57. C. Kuiper and M. Vissers, "Ascorbate as a co-factor for Fe- and 2-oxoglutarate dependent dioxygenases: physiological activity in tumor growth and progression," Frontiers in Oncolology, vol. 4, pp. 359, 2014.

58. C. Loenarz and C. J. Schofield, "Physiological and biochemical aspects of hydroxylations and demethylations catalyzed by human 2-oxoglutarate oxygenases," Trends in Biochemal Sciences, vol. 36, no. 1, pp. 7-18, 2011.

59. E. Flashman, S. L. Davies, K. K. Yeoh, et al., "Investigating the dependence of the hypoxia-inducible factor hydroxylases (factor inhibiting HIF and prolyl hydroxylase domain 2) on ascorbate and other reducing agents," Biochemal Journal, vol. 427, no. 1, pp. 135-142, 2010.

60. C. Kuiper, G. U. Dachs, M. J. Currie, et al., "Intracellular ascorbate enhances hypoxia-inducible factor (HIF)-hydroxylase activity and preferentially suppresses the HIF-1 transcriptional response," Free Radical Biology and Medicine, vol. 69, pp. 308-317, 2014.

61. P. R. Raghavan, "Metadichol ${ }^{\circledR}$, Vitamin $\mathrm{C}$ and GULO gene expression in mouse adipocytes," Biology and Medicine, vol. 10, no. 1, pp. 426, 2017.

62. P. R. Raghavan, "Metadichol® and Vitamin C increase in vivo, an open-label study," Vitamins and Minerals, vol. 6, pp. 163, 2017.

63. P. R. Raghavan, "Metadichol ${ }^{\circledR}$ induced high levels of Vitamin C: case studies," Vitamins and Minerals, vol. 6, pp. 169, 2017.

64. P. Creixell, J. Reimand, S. Haider et al., "Pathway and network analysis of cancer genomes," Nature Methods, vol. 12, no. 7, pp. 615-621, 2015.

65. A. L. Barabási, N. Gulbahce and J. Loscalzo, "Network medicine: a network-based approach to human disease," Nature Reviews Genetics, vol. 12, no. 1, pp. 56-68, 2011.

66. A. P. Davis, C. J. Grondin, R. J. Johnson et al., "The comparative toxicogenomics database: update 2019," Nucleic Acids Research, vol. 47, no. D1, pp. D948-D954, 2019.

67. K. Breuer, A. K.Foroushani, M. R. Laird et al., "InnateDB: systems biology of innate immunity and beyond-recent updates and continuing curation," Nucleic Acids Research, vol. 41, no. D1, pp. D1228-D1233, 2013.

68. G. Glinsky, "Genomics-guided molecular maps of coronavirus targets in human cells: a path toward the repurposing of existing drugs to mitigate the pandemic," arXiv:2003.13665, 2020.

69. M. B. Meyer, P. D. Goetsch and J. W. Pike, "VDR/RXR and TCF4/ $\beta$-catenin cistromes in colonic cells of colorectal tumor origin: impact on c-FOS and c-MYC gene expression," Molecular Endocrinology, vol. 26, no. 1, pp. 37-51, 2012.

70. B. S. An, L. E. Tavera-Mendoza, V. Dimitrov et al., "Stimulation of Sirt1-regulated FoxO protein function by the ligand-bound vitamin D receptor," Molecular and Cellular Biology, vol. 30, no. 20, pp. 4890-4900, 2010. 
71. Z. Lin, J. Li and D. Fang, “Sirt involvement in virus-mediated diseases," JSM Microbiology, vol. 1, no. 2, pp. 1006, 2013.

72. M. Fu, M. Liu, A. A. Sauve et al., "Hormonal control of androgen receptor function through SIRT1," Molecular and Cellular Biology, vol. 26, no. 21, pp. 8122-8135, 2006.

73. I. Rodchenkov, O. Babur, A. Luna et al., "Pathway commons 2019 update: integration, analysis and exploration of pathway data," Nucleic Acids Research, vol. 48, no. D1, pp. D489-D497, 2020.

74. C. G, Wambier and A. Goren, "Severe acute respiratory syndrome coronavirus 2 (SARS-CoV-2) infection is likely to be androgen mediated," Journal of the American Academy of Dermatology, vol. 83 , no. 1, pp. 308-309, 2020.

75. Y. C. Ma, C. Shi, Y. N. Zhang et al., "The tyrosine kinase c-Src directly mediates growth factor-induced Notch-1 and Furin interaction and Notch-1 activation in pancreatic cancer cells," PLoS One, vol. 7, no. 3, e33414, 2012.

76. C. Buitrago, G. Vazquez, A. R. De Boland et al., "Activation of Src kinase in skeletal muscle cells by 1,25-(OH)2-vitamin D3 correlates with tyrosine phosphorylation of the vitamin D receptor (VDR) and VDR-Src interaction," Journal of Cellular Biochemistry, vol. 79, no. 2, pp. 274-281, 2000.

77. A. Marchwicka and E. Marcinkowska, "Regulation of expression of CEBP genes by variably expressed Vitamin $D$ receptor and retinoic acid receptor a in human acute myeloid leukemia cell lines," International Journal of Molecular Sciences, vol. 19, no. 7, pp. 1918, 2018.

78. M. V. Arcidiacono, J. Yang, E. Fernandez et al., "The induction of C/EBP $\beta$ contributes to vitamin $D$ inhibition of ADAM17 expression and parathyroid hyperplasia in kidney disease," Nephrology Dialysis Transplantation, vol. 30, no. 3, pp. 423-433, 2015.

79. H. Ulrich and M. M. Pillat, "CD147 as a target for COVID-19 treatment: suggested effects of azithromycin and stem cell engagement," Stem Cell Reviews and Reports, vol. 16, no. 3, pp.434-440, 2020.

80. C. Crosnier, L.Y. Bustamante, S. J. Bartholdson et al., "Basigin is a receptor essential for erythrocyte invasion by Plasmodium falciparum," Nature, vol. 480, no. 7378, pp. 534-537, 2011.

81. K. Kuba, Y. Imai, S. Rao et al., "A crucial role of angiotensin converting enzyme 2 (ACE2) in SARS coronavirus-induced lung injury," Nature Medicine, vol. 11, no. 8, pp. 875-879, 2005.

82. S. Eguchi, T. Kawai, R. Scalia, et al., "Understanding angiotensin II type 1 receptor signaling in vascular pathophysiology," Hypertension, vol. 71, no. 5, pp. 804-810, 2018.

83. M. Murakami, D. Kamimura and T. Hirano, "Pleiotropy and specificity: insights from the interleukin 6 family of cytokines," Immunity, vol. 50, no. 4, pp. 812-831, 2019.

84. E. de Wit, N. van Doremalen, D. Falzarano et al., "SARS and MERS: recent insights into emerging coronaviruses," Nature Reviews Microbiology, vol. 14, no. 8, pp. 523-534, 2016.

85. S. F. Pedersen and Y. C. Ho, "SARS-CoV-2: a storm is raging," The Journal of Clinical Investigation, vol. 130, no. 5, pp. 2202-2205, 2020. 
86. W. Guo, M. Li, Y. Dong et al., "Diabetes is a risk factor for the progression and prognosis of COVID19," Diabetes/Metabolism Research and Reviews, vol. 36, no. 7, e3319, 2020.

87. C. Wu, X. Chen, Y. Cai et al., "Risk factors associated with acute respiratory distress syndrome and death in patients with coronavirus disease 2019 pneumonia in Wuhan, China," JAMA Internal Medicine, vol. 180, no. 7, pp 934-943, 2020.

88. P. R. Raghavan, "Systolic and diastolic BP control in metabolic syndrome patients with Metadichol ${ }^{\circ}$ a novel nano emulsion lipid," Journal of Cardiology \& Cardiovascular Therapy, vol. 5, Article ID: 555660, 2017.

89. P. R. Raghavan, "Metadichol and type 2 diabetes a case report," Journal of the Science of Healing Outcomes, vol. 8, pp. 5-10, 2016.

90. P. R. Raghavan, https://www.researchgate.net/profile/Palayakotai_Raghavan/publications.

\section{Tables}

Table 1. In vitro antiviral assay

\begin{tabular}{|l|l|l|l|}
\hline & CC $_{50}$ & EC $_{90}$ & SI $_{90}$ \\
\hline Metadichol $(\mu \mathrm{g} / \mathrm{mL})$ & 4 & 0.15 & 20 \\
\hline M128533 $(\mu \mathrm{g} / \mathrm{mL})$ & $>10$ & 0.2 & $>33$ \\
\hline
\end{tabular}

$\mathrm{CC}_{50}: 50 \%$ cytotoxic concentration of compound without virus added;

$\mathrm{EC}_{50}: 50 \%$ effective antiviral Concentration;

$\mathrm{EC}_{90}$ : calculated concentration to reduce viral yield by $1 \log (90 \%)$

SI: $\mathrm{CC}_{50} / \mathrm{EC}_{50}$.

Table 2. Cytotoxicity and viral yield data for each concentration of Metadichol tested 


\begin{tabular}{|c|c|c|}
\hline $\begin{array}{l}\text { Metadichol Concentration } \\
(\mu \mathrm{g} / \mathrm{mL})\end{array}$ & $\begin{array}{c}\text { Cytotoxicity } \\
(\%)\end{array}$ & $\begin{array}{c}\text { Viral Titer (CCID50 per 0.1 } \\
\mathrm{mL})\end{array}$ \\
\hline 100 & $100 \%$ & $<0.7$ \\
\hline 32 & $100 \%$ & $<0.7$ \\
\hline 10 & $83 \%$ & $<0.7$ \\
\hline 3.2 & $54 \%$ & 0.7 \\
\hline 1 & $17 \%$ & 4.3 \\
\hline 0.3 & $26 \%$ & 1.5 \\
\hline 0.1 & $26 \%$ & 5.7 \\
\hline 0.03 & $26 \%$ & 5.3 \\
\hline
\end{tabular}

CCID (Cell culture infectious dose 50\%/ml)

Table 3. Raw data of Metadichol Cytotoxicity in viral absence, as measured by using the neutral red assay. Units are $\mu \mathrm{g} / \mathrm{mL}$ unless noted

\begin{tabular}{|l|l|l|l|l|l|l|l|l|}
\hline & & & & & & & \multicolumn{2}{|l|}{} \\
\hline $\begin{array}{l}\text { Metadichol } \\
(\mathrm{gg} / \mathrm{mL})\end{array}$ & Adenovirus & Tacaribe & $\begin{array}{l}\text { Rift } \\
\text { valley }\end{array}$ & SARS & $\begin{array}{l}\text { Japanese } \\
\text { encephalitis }\end{array}$ & $\begin{array}{l}\text { West Nile } \\
\text { virus }\end{array}$ & \multicolumn{2}{|c|}{$\begin{array}{l}\text { Yellow fever } \\
\text { Powassan virus }\end{array}$} \\
\hline 500 & $95 \%$ & $98 \%$ & $96 \%$ & $96 \%$ & $100 \%$ & $100 \%$ & $100 \%$ & $100 \%$ \\
\hline 160 & $92 \%$ & $98 \%$ & $96 \%$ & $95 \%$ & $100 \%$ & $100 \%$ & $100 \%$ & $100 \%$ \\
\hline 50 & $90 \%$ & $97 \%$ & $97 \%$ & $95 \%$ & $100 \%$ & $100 \%$ & $100 \%$ & $100 \%$ \\
\hline 16 & $85 \%$ & $95 \%$ & $81 \%$ & $92 \%$ & $88 \%$ & $77 \%$ & $98 \%$ & $100 \%$ \\
\hline 5 & $0 \%$ & $23 \%$ & $26 \%$ & $35 \%$ & $33 \%$ & $28 \%$ & $35 \%$ & $44 \%$ \\
\hline 1.6 & $0 \%$ & $2 \%$ & $10 \%$ & $15 \%$ & $12 \%$ & $14 \%$ & $19 \%$ & $6 \%$ \\
\hline 0.5 & $0 \%$ & $3 \%$ & $9 \%$ & $0 \%$ & $2 \%$ & $3 \%$ & $2 \%$ & $0 \%$ \\
\hline 0.16 & $0 \%$ & $17 \%$ & $3 \%$ & $0 \%$ & $0 \%$ & $0 \%$ & $4 \%$ & $0 \%$ \\
\hline $\mathrm{CC}_{50}$ & 9.90 & 7.30 & 8.40 & 6.70 & 7.20 & 8.50 & 5.00 & 5.1 \\
\hline
\end{tabular}

$\mathrm{CC}_{50}: 50 \%$ cytotoxic concentration of compound without virus added.

Table 4. Antiviral assay of Metadichol against various viruses, as measured using the neutral red assay 


\begin{tabular}{|c|c|c|c|c|c|c|c|c|}
\hline $\begin{array}{l}\text { Metadichol } \\
(\mathrm{\mu g} / \mathrm{mL})\end{array}$ & Adenovirus & Tacaribe & $\begin{array}{l}\text { Rift } \\
\text { valley } \\
\text { fever }\end{array}$ & SARS & $\begin{array}{l}\text { Japanese } \\
\text { encephalitis }\end{array}$ & $\begin{array}{l}\text { West } \\
\text { Nile }\end{array}$ & $\begin{array}{l}\text { Yellow } \\
\text { fever }\end{array}$ & Powassan \\
\hline 5 & $100 \%$ & $31 \%$ & $100 \%$ & $0 \%$ & $56 \%$ & $84 \%$ & $70 \%$ & $53 \%$ \\
\hline 1.6 & $100 \%$ & $69 \%$ & $100 \%$ & $52 \%$ & $87 \%$ & $100 \%$ & $73 \%$ & $100 \%$ \\
\hline 0.5 & $100 \%$ & $97 \%$ & $100 \%$ & $100 \%$ & $100 \%$ & $100 \%$ & $95 \%$ & $100 \%$ \\
\hline 0.16 & $100 \%$ & $100 \%$ & $100 \%$ & $100 \%$ & $100 \%$ & $100 \%$ & $96 \%$ & $100 \%$ \\
\hline $\mathrm{EC}_{50}$ & $>9.9$ & 2.8 & $>8.4$ & 1.7 & $>7.2$ & $>8.5$ & $>5$ & $>5.1$ \\
\hline
\end{tabular}

$\mathrm{EC}_{50}: 50 \%$ effective antiviral concentration

Table 5. List of viruses inhibited by Metadichol in vitro

\begin{tabular}{|l|l|}
\hline Adenovirus & Rift valley \\
\hline Japanese encephalitis & Marburg \\
\hline Tacaribe & SARS (Severe acute respiratory syndrome ) \\
\hline Powassan & Respiratory syncytial virus \\
\hline Zika & Chikungunya \\
\hline Ebola & Influenza A (H1N1) \\
\hline Yellow fever & Dengue \\
\hline West Nile virus & HIV( human Immunodeficiency virus) \\
\hline
\end{tabular}

Table 6. TMPRSS2 assay data 


\begin{tabular}{|c|c|c|c|c|}
\hline Sample & Concentration & RFU & \% Inhibition & $\mathrm{IC}_{50}$ \\
\hline Control & 0 & 43233358 & 0.00 & \\
\hline \multirow[t]{7}{*}{ Metadichol (ng/mL) } & 1.56 & 41305150 & 4.46 & $96.65 \mathrm{ng} / \mathrm{mL}$ \\
\hline & 3.12 & 39329385 & 9.03 & \\
\hline & 6.25 & 36713767 & 15.08 & \\
\hline & 12.5 & 33778222 & 21.87 & \\
\hline & 25 & 30695684 & 29.00 & \\
\hline & 50 & 26087008 & 39.66 & \\
\hline & 100 & 16009312 & 62.97 & \\
\hline \multicolumn{5}{|c|}{ Camostat mesylate $(\mu \mathrm{g} / \mathrm{mL})$} \\
\hline & 0.78 & 37984828 & 12.14 & $26.46 \mu \mathrm{g} / \mathrm{mL}$ \\
\hline & 1.56 & 35235186 & 18.50 & \\
\hline & 3.125 & 31685728 & 26.71 & \\
\hline & 6.25 & 29234396 & 32.38 & \\
\hline & 12.5 & 23276839 & 46.16 & \\
\hline & 25 & 18931887 & 56.21 & \\
\hline & 50 & 8797988 & 79.65 & \\
\hline
\end{tabular}

Table 7. ACE2 assay data 


\begin{tabular}{|c|c|c|c|c|}
\hline Sample & Concentration $(\mu \mathrm{g} / \mathrm{mL})$ & RFU & \% Inhibition & $\mathrm{IC}_{50}(\mu \mathrm{g} / \mathrm{mL})$ \\
\hline Control & 0 & 308315546 & 0.00 & \\
\hline \multirow[t]{7}{*}{ Metadichol } & 0.125 & 290309918 & 5.84 & 30.15 \\
\hline & 0.25 & 260064163 & 15.65 & \\
\hline & 0.5 & 249149792 & 19.19 & \\
\hline & 1 & 240301136 & 22.06 & \\
\hline & 10 & 212275253 & 31.15 & \\
\hline & 20 & 187702504 & 39.12 & \\
\hline & 40 & 139821100 & 54.65 & \\
\hline \multirow[t]{6}{*}{ DX600 } & 0.0156 & 252855648 & 17.99 & 0.1027 \\
\hline & 0.031 & 231028864 & 25.07 & \\
\hline & 0.0625 & 193810784 & 37.14 & \\
\hline & 0.125 & 145881248 & 52.68 & \\
\hline & 0.25 & 127485752 & 58.65 & \\
\hline & 0.5 & 111498760 & 63.84 & \\
\hline
\end{tabular}

Table 8. ACE assay data 


\begin{tabular}{|c|c|c|}
\hline Captopril (control) & Concentration ng/mL & Percent Inhibition \\
\hline & 0.63 & 6.12 \\
\hline & 1.25 & 15.04 \\
\hline & 2.50 & 32.42 \\
\hline & 5.00 & 43.5 \\
\hline & 10.00 & 57.2 \\
\hline & 20 & 76.51 \\
\hline \multirow[t]{9}{*}{ Metadichol } & 3.9 & 4.61 \\
\hline & 7.8 & 6.37 \\
\hline & 15.6 & 14.28 \\
\hline & 31.25 & 22.59 \\
\hline & 62.5 & 36.71 \\
\hline & 125 & 54.89 \\
\hline & 250 & 60.51 \\
\hline & 500 & 66.23 \\
\hline & 1000 & 78.1 \\
\hline
\end{tabular}

Table 9 Disease network of the 13 curated genes 


\begin{tabular}{|c|c|c|c|c|}
\hline Disease name & Disease categories & $\begin{array}{l}\text { Corrected } \\
\text { p-value }\end{array}$ & $\begin{array}{l}\text { Annotated } \\
\text { gene } \\
\text { quantity }\end{array}$ & Annotated genes \\
\hline COVID-19 & $\begin{array}{l}\text { Respiratory tract disease, viral } \\
\text { disease }\end{array}$ & $3.10 \mathrm{E}-47$ & 13 & $\begin{array}{l}\text { ACE2, AGT, CCL2, CCL3, CSF3, } \\
\text { CXCL10, IL10, IL2, IL2RA, IL6, IL7, } \\
\text { TMPRSS2, TNF }\end{array}$ \\
\hline $\begin{array}{l}\text { Pneumonia, } \\
\text { viral }\end{array}$ & $\begin{array}{l}\text { Respiratory tract disease, viral } \\
\text { disease }\end{array}$ & $4.34 \mathrm{E}-46$ & 13 & $\begin{array}{l}\text { ACE2, AGT, CCL2, CCL3, CSF3, } \\
\text { CXCL10, IL10, IL2, IL2RA, IL6, IL7, } \\
\text { TMPRSS2, TNF }\end{array}$ \\
\hline $\begin{array}{l}\text { Coronaviridae } \\
\text { infections }\end{array}$ & Viral disease & $1.74 \mathrm{E}-44$ & 13 & $\begin{array}{l}\text { ACE2, AGT, CCL2, CCL3, CSF3, } \\
\text { CXCL10, IL10, IL2, IL2RA, IL6, IL7, } \\
\text { TMPRSS2, TNF }\end{array}$ \\
\hline $\begin{array}{l}\text { Coronavirus } \\
\text { infections }\end{array}$ & Viral disease & $1.74 \mathrm{E}-44$ & 13 & $\begin{array}{l}\text { ACE2, AGT, CCL2, CCL3, CSF3, } \\
\text { CXCL10, IL10, IL2, IL2RA, IL6, IL7, } \\
\text { TMPRSS2, TNF }\end{array}$ \\
\hline $\begin{array}{l}\text { Nidovirales } \\
\text { infections }\end{array}$ & Viral disease & $1.74 \mathrm{E}-44$ & 13 & $\begin{array}{l}\text { ACE2, AGT, CCL2, CCL3, CSF3, } \\
\text { CXCL10, IL10, IL2, IL2RA, IL6, IL7, } \\
\text { TMPRSS2, TNF }\end{array}$ \\
\hline $\begin{array}{l}\text { RNA virus } \\
\text { infections }\end{array}$ & Viral disease & $4.92 \mathrm{E}-27$ & 13 & $\begin{array}{l}\text { ACE2, AGT, CCL2, CCL3, CSF3, } \\
\text { CXCL10, IL10, IL2, IL2RA, IL6, IL7, } \\
\text { TMPRSS2, TNF }\end{array}$ \\
\hline Virus diseases & Viral disease & $1.73 \mathrm{E}-25$ & 13 & $\begin{array}{l}\text { ACE2, AGT, CCL2, CCL3, CSF3, } \\
\text { CXCL10, IL10, IL2, IL2RA, IL6, IL7, } \\
\text { TMPRSS2, TNF }\end{array}$ \\
\hline $\begin{array}{l}\text { Sexually } \\
\text { transmitted } \\
\text { diseases, viral }\end{array}$ & Viral disease & $1.38 \mathrm{E}-12$ & 7 & $\begin{array}{l}\text { CCL2, CCL3, IL10, IL2, IL2RA, IL6, } \\
\text { TNF }\end{array}$ \\
\hline HIV infections & $\begin{array}{l}\text { Immune system disease, viral } \\
\text { disease }\end{array}$ & $1.56 \mathrm{E}-12$ & 7 & $\begin{array}{l}\text { CCL2, CCL3, IL10, IL2, IL2RA, IL6, } \\
\text { TNF }\end{array}$ \\
\hline $\begin{array}{l}\text { Lentivirus } \\
\text { infections }\end{array}$ & Viral disease & $1.56 \mathrm{E}-12$ & 7 & $\begin{array}{l}\text { CCL2, CCL3, IL10, IL2, IL2RA, IL6, } \\
\text { TNF }\end{array}$ \\
\hline $\begin{array}{l}\text { Retroviridae } \\
\text { infections }\end{array}$ & Viral disease & $1.56 \mathrm{E}-12$ & 7 & $\begin{array}{l}\text { CCL2, CCL3, IL10, IL2, IL2RA, IL6, } \\
\text { TNF }\end{array}$ \\
\hline $\begin{array}{l}\text { HIV wasting } \\
\text { syndrome }\end{array}$ & $\begin{array}{l}\text { Immune system disease, } \\
\text { metabolic disease, nutrition } \\
\text { disorder, viral disease }\end{array}$ & $4.00 \mathrm{E}-04$ & 2 & IL6, TNF \\
\hline $\begin{array}{l}\text { Coxsackievirus } \\
\text { infections }\end{array}$ & Viral disease & 0.001 & 2 & IL6, TNF \\
\hline $\begin{array}{l}\text { Enterovirus } \\
\text { infections }\end{array}$ & Viral disease & 0.0044 & 2 & IL6, TNF \\
\hline $\begin{array}{l}\text { Picornaviridae } \\
\text { infections }\end{array}$ & Viral disease & 0.00519 & 2 & IL6, TNF \\
\hline
\end{tabular}


Table 10 Disease network of genes implicated in the SARS-CoV-2 infection

\begin{tabular}{|l|l|l|l|l|}
\hline Disease name & p-value & Corrected p-value & Genes & Annotated genes \\
\hline COVID-19 & $1 \mathrm{E}-18$ & $5.44 \mathrm{E}-16$ & 5 & ACE2, AGT, CCL2, TMPRSS2, TNF \\
\hline Pneumonia, viral & $1.56 \mathrm{E}-18$ & $8.46 \mathrm{E}-16$ & 5 & ACE2, AGT, CCL2, TMPRSS2, TNF \\
\hline Coronaviridae infections & $3.4 \mathrm{E}-18$ & $1.85 \mathrm{E}-15$ & 5 & ACE2, AGT, CCL2, TMPRSS2, TNF \\
\hline Coronavirus infections & $3.4 \mathrm{E}-18$ & $1.85 \mathrm{E}-15$ & 5 & ACE2, AGT, CCL2, TMPRSS2, TNF \\
\hline Nidovirales infections & $3.4 \mathrm{E}-18$ & $1.85 \mathrm{E}-15$ & 5 & ACE2, AGT, CCL2, TMPRSS2, TNF \\
\hline Pneumonia & $9.42 \mathrm{E}-15$ & $5.11 \mathrm{E}-12$ & 5 & ACE2, AGT, CCL2, TMPRSS2, TNF \\
\hline Respiratory tract infections & $3.13 \mathrm{E}-13$ & $1.7 \mathrm{E}-10$ & 5 & ACE2, AGT, CCL2, TMPRSS2, TNF \\
\hline RNA virus infections & $2.46 \mathrm{E}-12$ & $1.34 \mathrm{E}-09$ & 5 & ACE2, AGT, CCL2, TMPRSS2, TNF \\
\hline Virus diseases & $9.48 \mathrm{E}-12$ & $5.15 \mathrm{E}-09$ & 5 & ACE2, AGT, CCL2, TMPRSS2, TNF \\
\hline
\end{tabular}

\section{Glossary Of Gene Descriptions}




\begin{tabular}{|c|c|}
\hline Gene & Description \\
\hline VDR & vitamin D receptor \\
\hline AHR & aryl hydrocarbon receptor \\
\hline TERT & telomerase reverse transcriptase \\
\hline KL & klotho \\
\hline PAI1 (SERPINE1) & serpin family $\mathrm{E}$ member 1 \\
\hline HIF 1 alpha & hypoxia-inducible factor 1-alpha \\
\hline CCL2 & C-C motif chemokine ligand 2 \\
\hline ICAM1 & intercellular adhesion molecule 1 \\
\hline TNF & tumor necrosis factor \\
\hline $\mathrm{ACE}$ & angiotensin I-converting enzyme \\
\hline ACE2 & angiotensin I-converting enzyme 2 \\
\hline AGTR1 (ANG1) & angiotensin II receptor type 1 \\
\hline AGTR2 (ANG2) & angiotensin II receptor type 2 \\
\hline TMPRSS2 & transmembrane serine protease 2 \\
\hline SIRT1 & sirtuin 1 \\
\hline FURIN & furin, paired basic amino acid cleaving enzyme \\
\hline CD 147 (BSG) & Basigin (BSG), also known as extracellular matrix metalloproteinase inducer \\
\hline IL6 & interleukin 6 \\
\hline IL10 & interleukin 10 \\
\hline CCL3 & C-C motif chemokine ligand 3 \\
\hline IL2 & interleukin 2 \\
\hline IL7 & interleukin 7 \\
\hline CSF3 & Colony-stimulating factor 3 \\
\hline IL2RA & interleukin 2 receptor subunit alpha \\
\hline CXCL8 & C-X-C motif chemokine ligand 8 \\
\hline
\end{tabular}

\section{Figures}




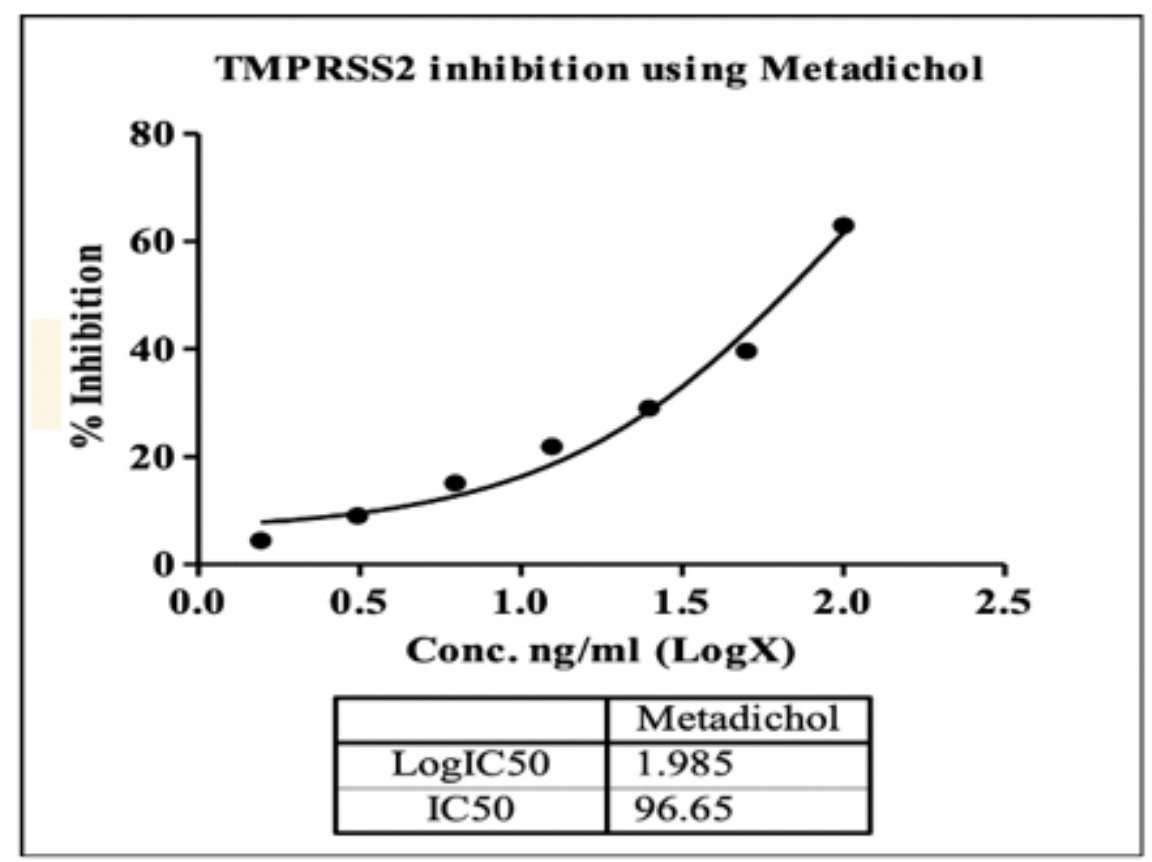

Figure 2

Inhibition of TMPRSS2 by Metadichol

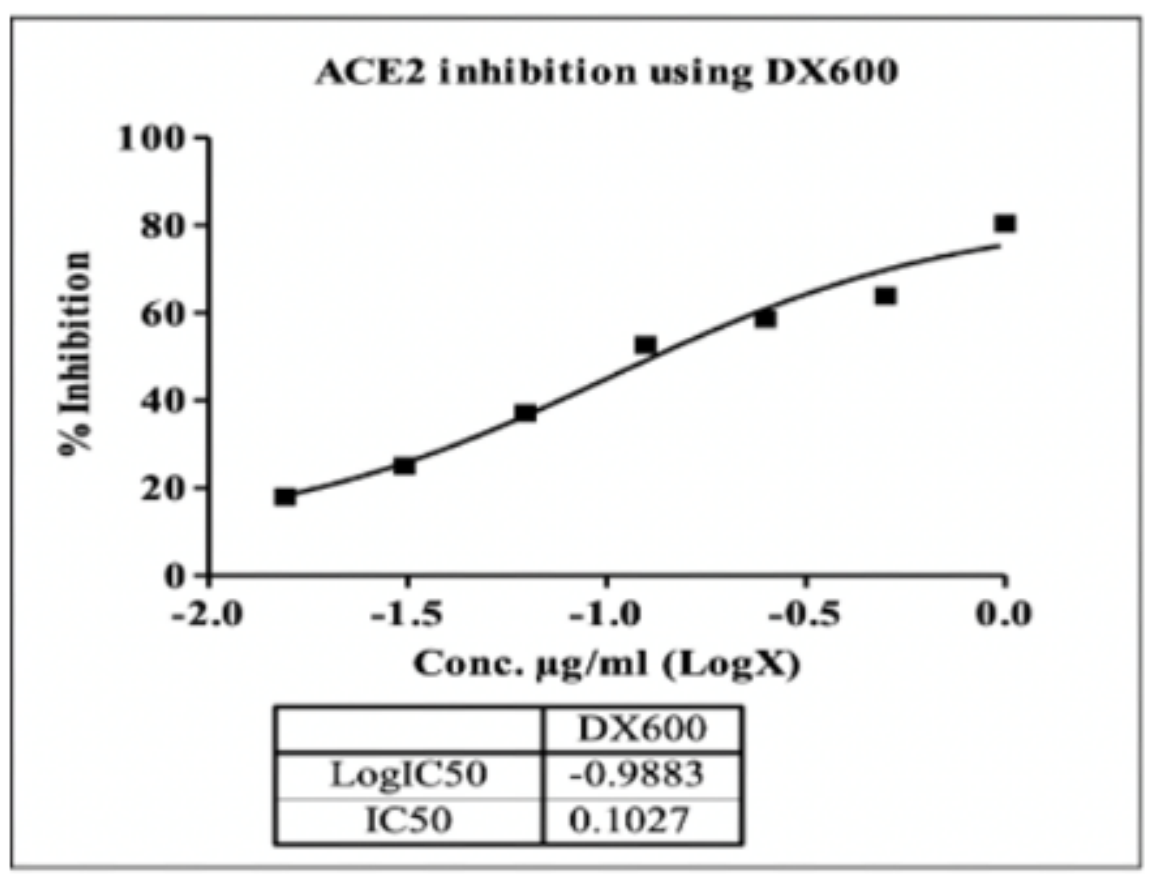

Figure 3

Inhibition of ACE2 by DX600 (control) 


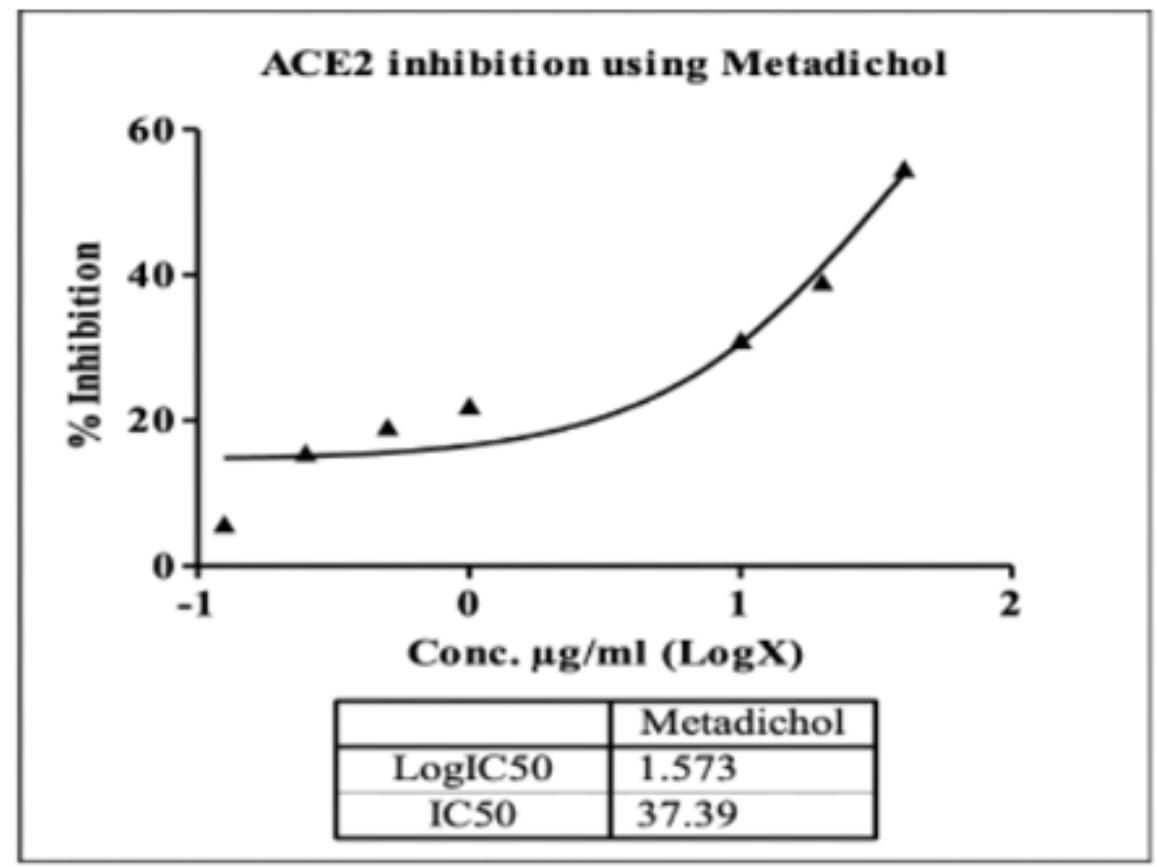

Figure 4

Inhibition of ACE2 by Metadichol

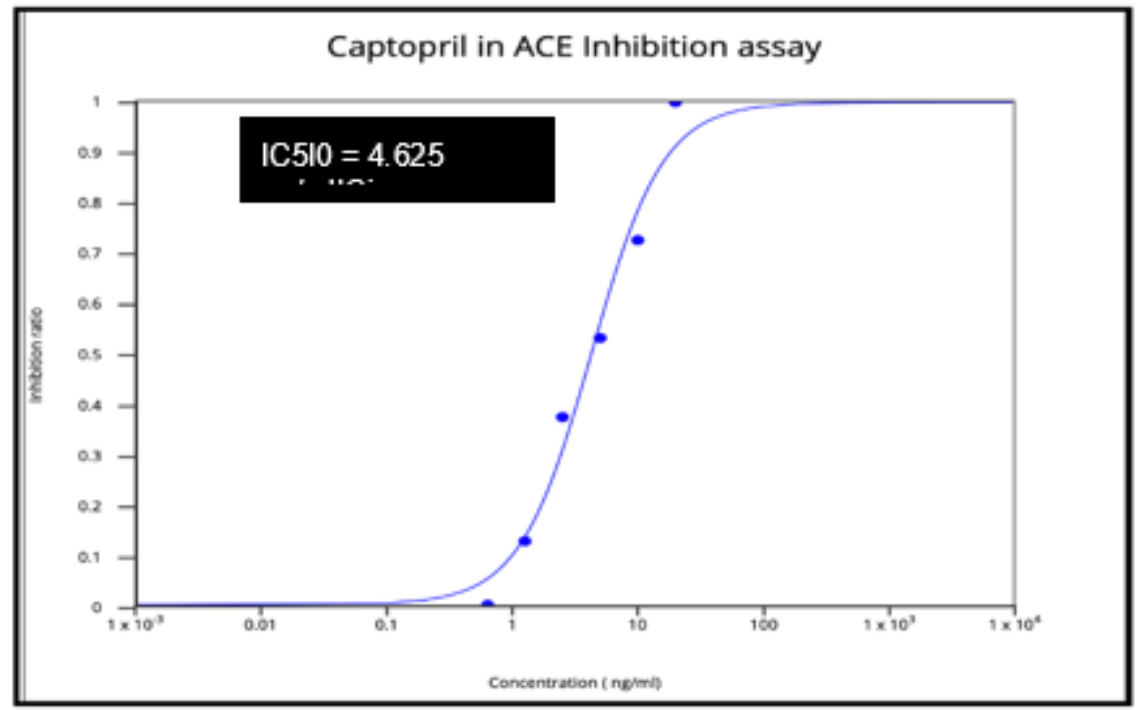

Figure 5

Inhibition of ACE by captopril (control) 


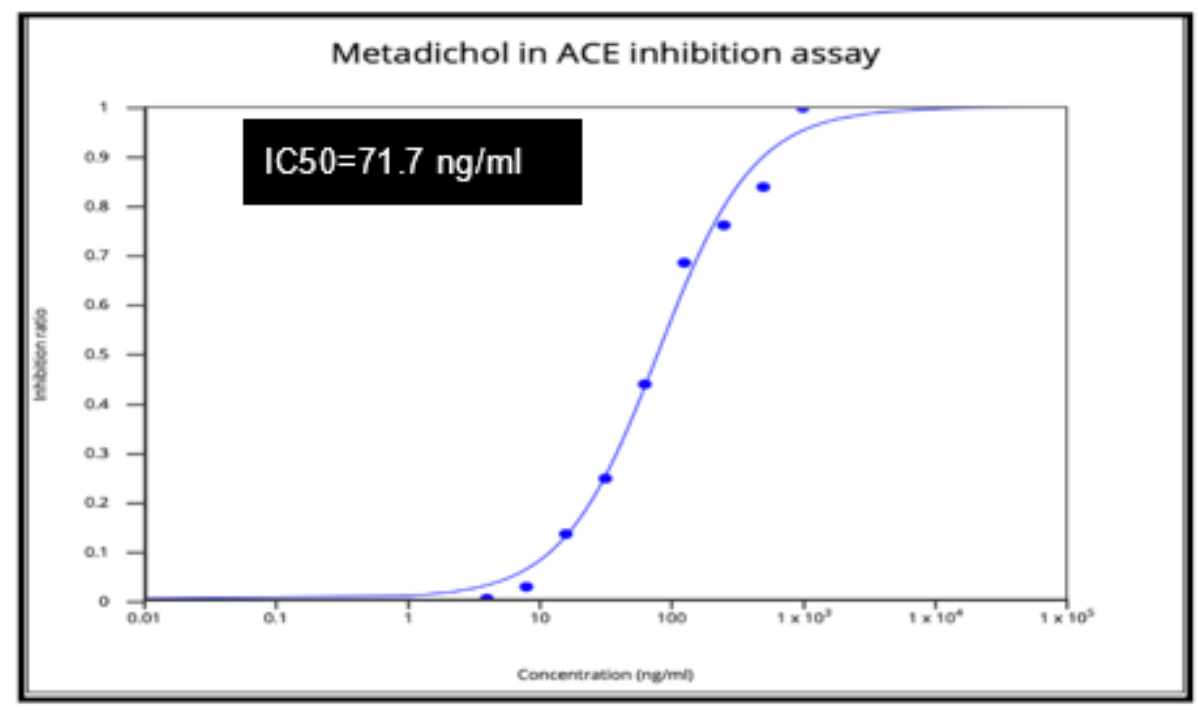

Figure 6

Inhibition of ACE by Metadichol. IC 50 is the concentration of drug required for $50 \%$ inhibition. $\mathrm{ug} / \mathrm{ml}$ is micrograms per $\mathrm{ml} . \mathrm{ng} / \mathrm{ml}$ is nanograms per $\mathrm{ml}$ 

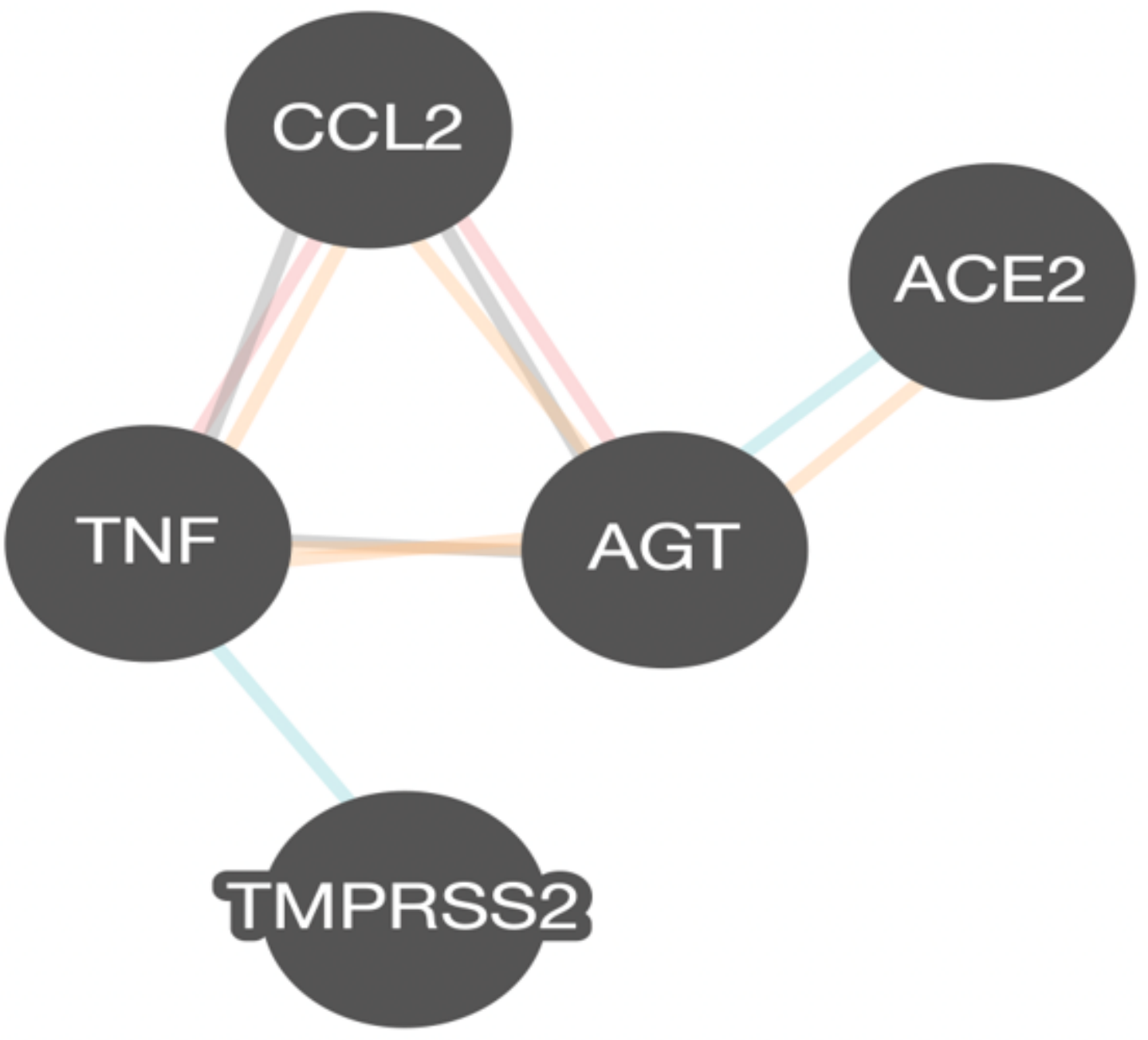

\begin{tabular}{|l|l|}
\hline Gene & Description \\
\hline CCL2 & C-C motif chemokine ligand 2 \\
\hline AGT & Angiotensinogen \\
\hline TNF & tumor necrosis factor \\
\hline TMPRSS2 & transmembrane serine protease 2 \\
\hline ACE2 & $\begin{array}{l}\text { angiotensin I-converting enzyme } \\
2\end{array}$ \\
\hline
\end{tabular}

Figure 7

Potential key gene targets in the SARS-CoV-2 infection 


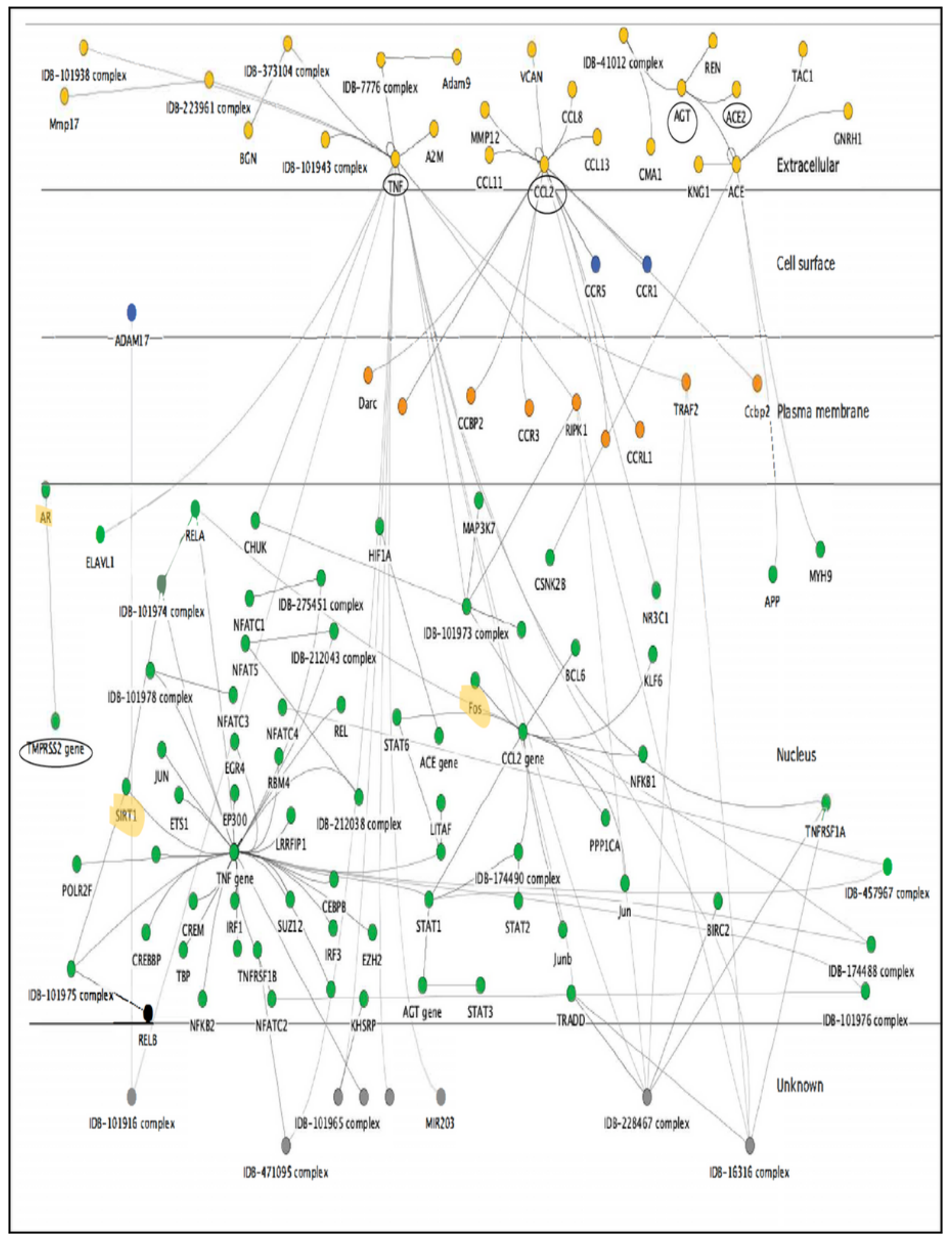

\section{Figure 8}

Network analysis of the genes involved in the SARS-CoV-2 infections 


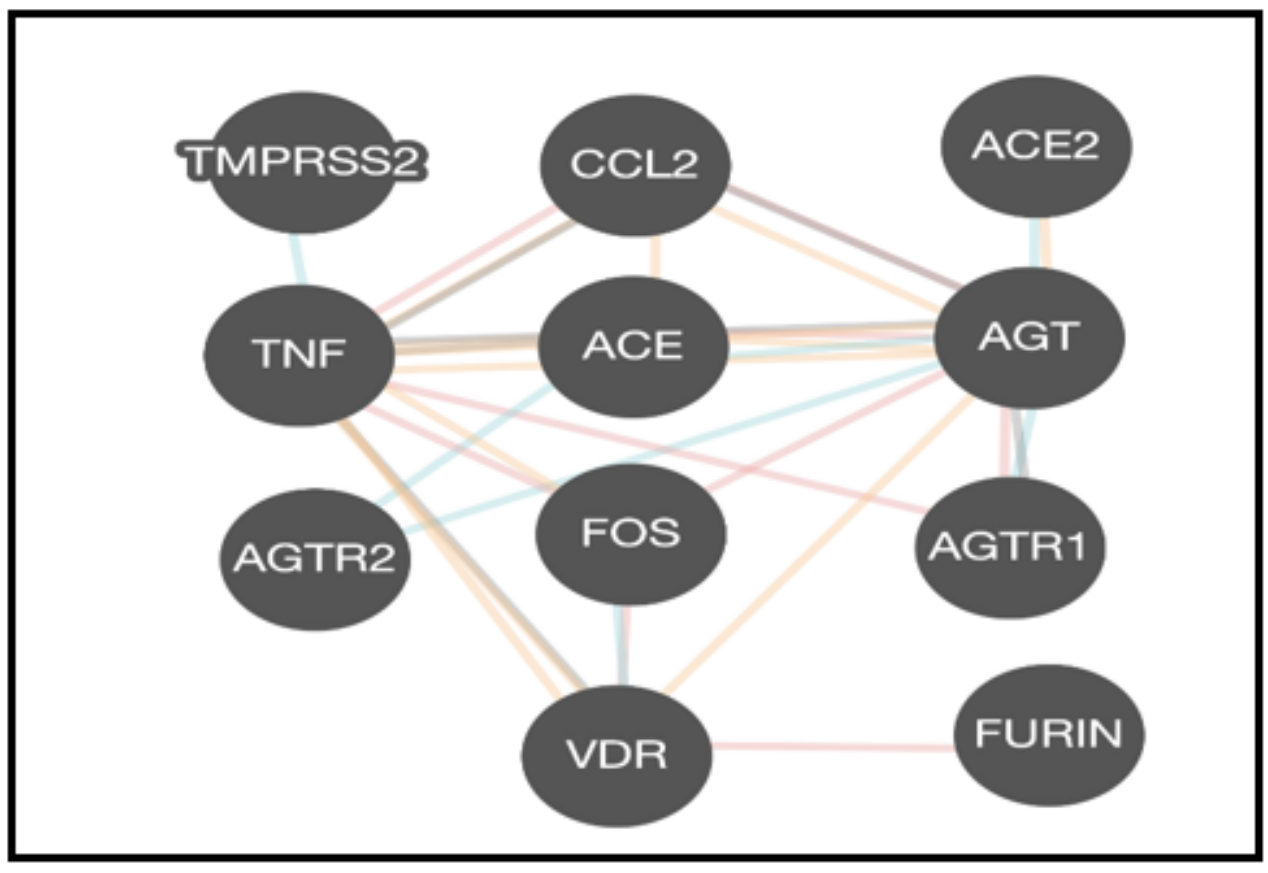

\begin{tabular}{|l|l|}
\hline Gene & Description \\
\hline VDR & vitamin D receptor \\
\hline CCL2 & C-C motif chemokine ligand 2 \\
\hline AGT & Angiotensinogen \\
\hline TNF & tumor necrosis factor \\
\hline TMPRSS2 & transmembrane serine protease 2 \\
\hline ACE2 & angiotensin I-converting enzyme 2 \\
\hline AGTR1 (ANG1) & angiotensin II receptor type 1 \\
\hline AGTR2 (ANG2) & angiotensin II receptor type 2 \\
\hline FOS & $\begin{array}{l}\text { Fos Proto-Oncogene, AP-1 } \\
\text { Transcription Factor Subuni }\end{array}$ \\
\hline FURIN & $\begin{array}{l}\text { furin, paired basic amino acid cleaving } \\
\text { enzyme }\end{array}$ \\
\hline ACE & angiotensin I-converting enzyme \\
\hline
\end{tabular}

\section{Figure 9}

Network of relationship between the vitamin D receptor and RAAs 


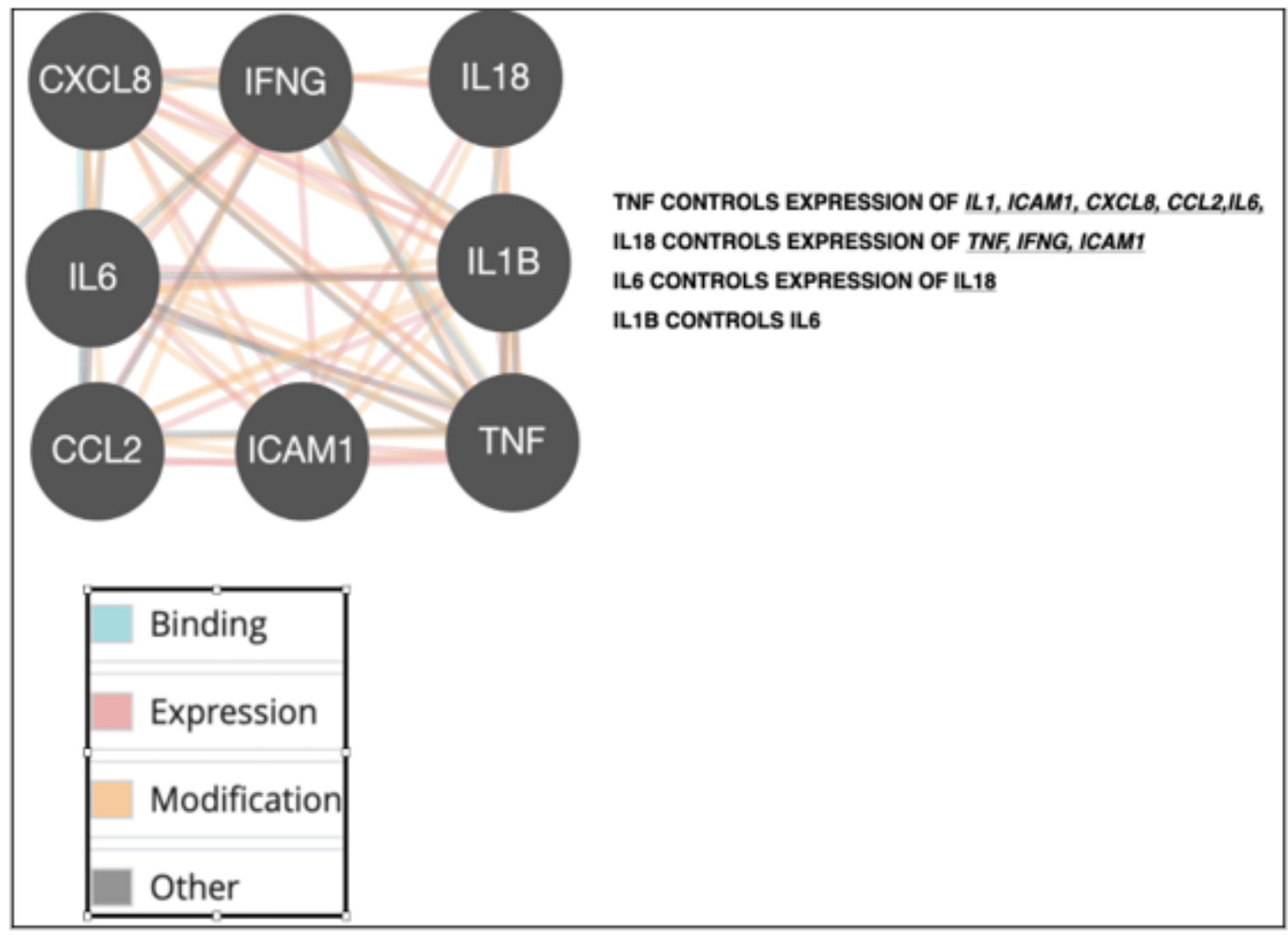

\begin{tabular}{|l|l|}
\hline Gene & Description \\
\hline CCL2 & C-C motif chemokine ligand 2 \\
\hline ICAM1 & intercellular adhesion molecule 1 \\
\hline TNF & tumor necrosis factor \\
\hline IL6 & interleukin 6 \\
\hline CXCL8 (IL8) & C-X-C motif chemokine ligand 8 \\
\hline IL1B & Interleukin 1 beta \\
\hline IL18 & Interleukin 18 \\
\hline IFNG & Interferon gamma \\
\hline
\end{tabular}

\section{Figure 10}

Gene-cytokine relationships 


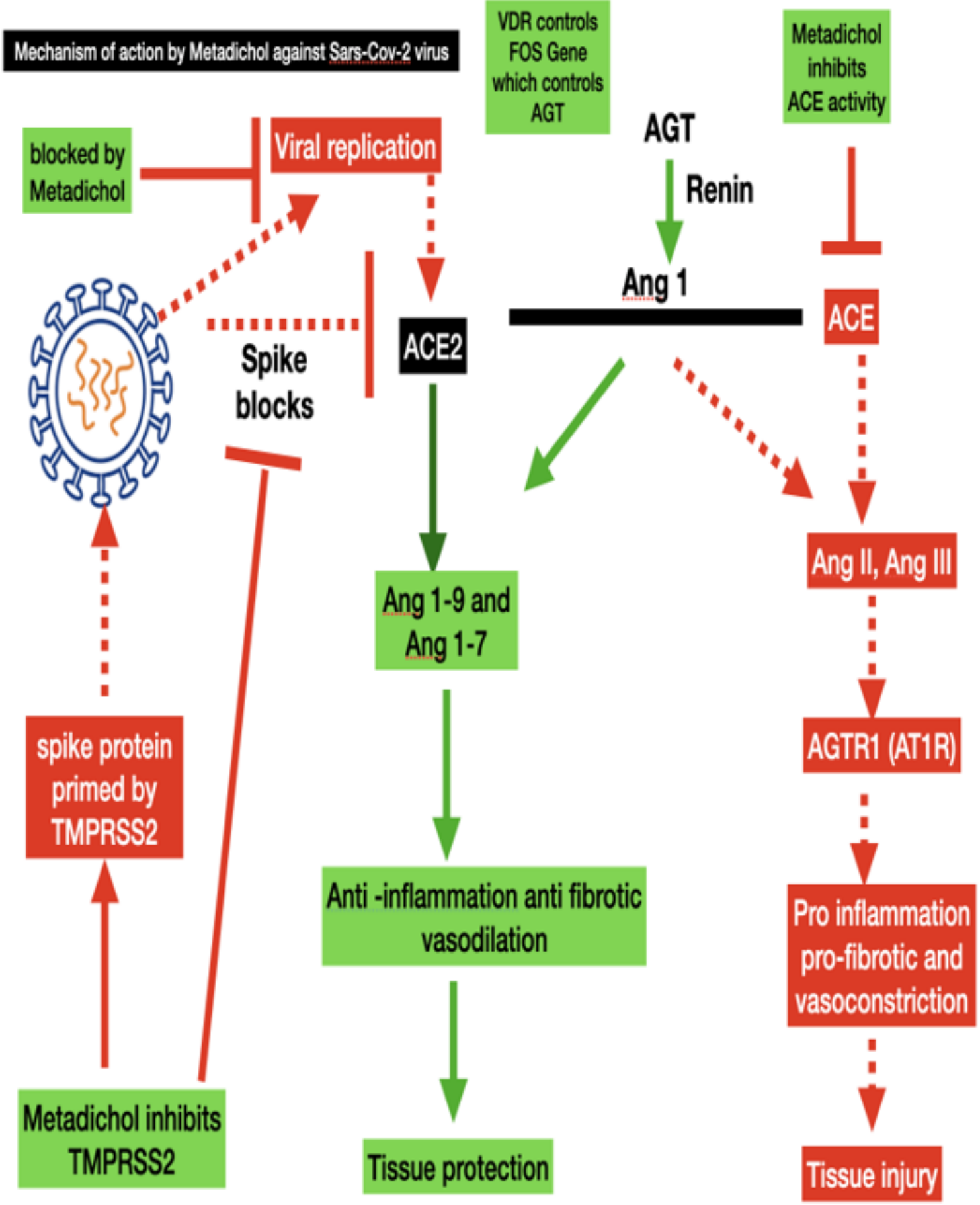

Figure 11

Mechanism of action of Metadichol against SARS-CoV-2 virus

\section{Supplementary Files}

This is a list of supplementary files associated with this preprint. Click to download. 
- Supplementaymaterial.pdf

Page 34/34 